EstAg 32 (1997) 431-498

\title{
La propuesta de Lindbeck acerca de las doctrinas religiosas.
}

\author{
Hacia una visión postliberal de la Teología
}

\section{INTRODUCCIÓN}

En 1984 publicó Lindbeck ${ }^{1}$ un escueto libro de seis capítulos titulado The Nature of Doctrine. Religion and Theology in a Postliberal Age ${ }^{2}$. La obra alcanzó de forma rápida una gran resonancia en medios teológicos anglosajones recibiendo comentarios, observaciones y respuestas de toda índole ${ }^{3}$. En el continente europeo el libro pasó prácticamente desapercibido ${ }^{4}$. La obra

1. George A. Lindbeck, profesor de Teología en la Yale Divinity School (Universidad de Yale) hasta 1994. Nacido en 1924 y educado en Minnesota y Yale. De confesión luterana, fue observador en el Concilio Vaticano II. Sus preocupaciones teológicas se han centrado en el ecumenismo teniendo una participación activa en los diálogos mantenidos entre las Iglesias católica y luterana, ocupando además puestos de responsabilidad en la comisión católico-luterana, véase (Ford 1994, II, x) y (Lindbeck 1984, 26,n.1). La lista de sus publicaciones, junto con su actividad ecuménica, puede verse en (Marshall 1990, 283-298) y, más completa, en (Lindbeck 1994a, 199-206).

2. Desde ahora abreviado ND. Publicado por Westminster Press (Philadelphia) / SPCK (Londres). Es un libro de sólo 142 páginas. Según confiesa el autor la obra recoge ideas que ya comenzó a exponer en una serie de conferencias dictadas en 1974 en la Gonzaga University (ND 12).

3. Tuvo recensiones, entre otras, en Expository Times (Macquarrie 1984-85); Journal of Theological Studies (Ford 1986); Modern Theology (Corner 1986); The Journal of Religion (Gerrish 1988). La revista The Thomist le dedicó un número monográfico en julio de 1985 recogiendo las ponencias de un congreso tenido sobre el libro. Lo mismo hizo Modern Theology con su segundo número de 1988. Obra de reconocimiento a Lindbeck es (Marshall 1990). La bibliografía sobre su obra es muy numerosa como puede verse al final del artículo. Incluso hay tesis doctorales sobre el tema, así (Barrigar 1995), (Elkins 1993) o (Herholdt 1992).

4. El libro fue recensionado en la Theologische Revue (Wiedenhofer 1988) y comentado en Evangelische Theologie (Wainwright 1986). Recientemente ha sido traducido al alemán con un nuevo prólogo añadido por el autor: Christliche Lehre als Grammatik des Glaubens. 
bien merece un breve comentario pues Lindbeck ha presentado una de las propuestas más innovadoras que hay en la actualidad sobre qué es una religión y, más en particular, sobre qué son las afirmaciones de fe que una religión hace. La alternativa que da el autor desemboca en una nueva forma de entender la teología. Aboga por una teología postliberal.

En primer lugar haremos un resumen muy sucinto del libro. Un segundo apartado tratará algunos de los factores que más han podido influir en la postura de Lindbeck. Para finalizar expondremos algunos comentarios críticos.

\section{PROPUESTA DE LINDBECK}

Brevemente vamos a exponer algunas de las ideas clave del libro.

\subsection{Consideraciones previas}

Lindbeck se centra en la naturaleza de lo que él llama doctrinas religiosas, es decir, en los sistemas de creencias que -en sentido amplio-constituyen lo característico de cada religión. Las doctrinas abarcan los dogmas en sentido estricto, pero también otra serie de creencias no tan solemnemente formulądas e, incluso, las normas de acción que dirigen el comportamiento de los creyentes 5 .

Según sea nuestra comprensión de lo que son las doctrinas, así tendremos una determinada concepción de lo que es una religión. El análisis, por lo tanto, no se circunscribirá a las doctrinas, sino que pretenderá ser también una teoría de la religión en sentido más amplio. De hecho, en la práctica, el autor hace primero una teoría de la religión y después aclara el concepto de doctrina.

Añade Lindbeck que, dado que su trabajo se enmarca dentro de una teoría general de la religión, entonces sus propuestas no son específicamente teológicas o cristianas. Va a ser así en el ideal, pero en la práctica el asunto del

Religion und Theologie im postliberalen Zeitalter (Kaiser: Gutersloh 1994). Una amplia recensión de la traducción se encuentra en Theologische Literaturzeitung (Albrecht 1995) y también en Theologisch-praktische Quartalschrift (Eckerstorfer 1997). Ver igualmente (Ott 1994, 128131).

5. "...norms of communal belief and action which are generally spoken of as the doctrines or dogmas of churches" (ND 7). Lindbeck emplea el concepto de dogma en forma muy laxa. Prefiere utilizar el término doctrina en sentido amplio. 
libro es el cristianismo ${ }^{6} \mathrm{y}$ el motivo que le ha impulsado a escribirlo ha sido su experiencia en actividades ecuménicas. Sus preocupaciones son, pues, más teológicas que teoréticas ${ }^{7}$ y tendrán como resultado final una nueva forma de comprender la religión cristiana y su credo. El autor la va a llamar postliberal, teología postliberal.

\subsection{Tres formas de comprensión de lo religioso}

Las teorías teológicas acerca de la religión y su contenido doctrinal se pueden clasificar en tres tipos ${ }^{8}$.

\subsubsection{Comprensión proposicional de la religión}

Es aquella que insiste en los aspectos cognitivos de la religión, en su contenido proposicional, es decir, en su cuerpo de doctrina. En esta concepción se considera lo fundamental de una religión al conjunto de enunciados informativos que hace acerca de una realidad objetiva ${ }^{9}$. Tales enunciados, como es obvio, se consideran verdaderos. Se concibe la religión en forma similar a como se ha entendido tradicionalmente la ciencia o la filosofía: conjunto de proposiciones verdaderas que nos informan acerca de un aspecto de la realidad, o de la realidad en su conjunto ${ }^{10}$. Esta postura, afirma Lindbeck, estaría cada vez más a la defensiva. Sería una posición preliberal en la que se piensa que la religión está exenta de error y se defiende la típica idea de revelación y de depósito de la fe ${ }^{11}$. Las religiones distintas de la nuestra podrían tener un conjunto de enunciados verdaderos, pero también otra serie de ellos falsos. Queda imposibilitada cualquier reconciliación doctrinal si no se realiza una capitulación de principios ${ }^{12}$.

7. "This suggests, quite rightly, that the motivations for this book are ultimately more substantively theological than purely theoretical. As one who is deeply concerned about Christian unity" (ND 10).

8. Los resume en (ND 16-17) y aparecen continuamente a lo largo de la obra.

9. "Church doctrines function as informative propositions or truth claims about objective realities" (ND 16).

10. "Religions are thus thought of as similiar to philosophy or science as these were classically conceived" (ND 16).

11. Como ejemplo paradigmático de esta noción de religión podríamos considerar nosotros la autocomprensión de la Iglesia católica tal y como se expresa en el Catecismo de la Iglesia Católica.

12. Dicho lo cuál no hay ecumenismo posible, véase ( $N D 16)$. 


\subsubsection{Comprensión expresivo-experiencial de la religión}

Un segunda forma de entender lo religioso insiste en la dimensión experiencial y expresiva de la religión y considera que los contenidos doctrinales no son informativos acerca de una realidad objetiva. Es la visión liberal de la religión. El credo no es lo decisivo de la religión pues las creencias no son realmente enunciados, sino manifestación o expresión simbólica de sentimientos, experiencias, actitudes internas $\mathrm{u}$ orientaciones existenciales ${ }^{13}$. Se considera la religión en forma parecida a lo que es la experiencia estética. Esta idea surge de las tendencias liberales que comenzaron con Schleiermacher y habría ido en ascenso con el paso del tiempo. No se podría -por lo tanto- hablar de una religión verdadera, sino de las diferentes religiones como objetivaciones de las mismas experiencias humanas básicas ${ }^{14}$. Esta concepción de lo religioso lleva a pensar, por ejemplo, que el budismo y el cristianismo son en el fondo la misma fe aunque expresadas de forma diferente ${ }^{15}$.

En ocasiones esta forma de entender lo religioso se entremezcla con la primera. Sería una vía intermedia que intentaría combinar ambas. Habría a la vez una insistencia tanto en los aspectos cognitivos como en los simbólicos y expresivos de la religión. Gran parte de la teología postconciliar, especialmente la católica, debería incluirse aquí. Rahner, Lonergan y otros serían representantes típicos de esta corriente.

\subsubsection{Comprensión linguiístico-cultural de la religión}

Frente a las dos posturas anteriores presenta Lindbeck otra posibilidad. Propone una alternativa que no se centra ni en el aspecto cognitivo, ni en el expresivo-experiencial de la religión, sino que pone el énfasis en aquellas características que hacen de una religión algo semejante a un lenguaje o a una cultura ${ }^{16}$.

13. "... interprets doctrines as noninformative and nondiscursive symbols of inner feelings, attitudes or existential orientations" (ND 16).

14. A esta línea pueden hacerse aproximaciones desde la fenomenología de la religión y, así, acentuar una experiencia común de lo sagrado que puede poseer la especie humana. Las religiones serían respuesta a ella. Es el caso de Otto o de Mircea Eliade. También caben lecturas desde otro punto de vista: recalcar las necesidades individuales de sentido de la vida, tal y como recuerdan Luckmann o Berger por ejemplo. Se insiste entonces en el papel de la religión proporcionando bienestar o realización personal, véase (ND 22). En ambas visiones se diluye la importancia de los credos.

15. Con lo cuál, no haría falta ningún tipo de ecumenismo, véase (ND 17).

16. "... it is similar to an idiom that makes possible the description of realities, the formulation of beliefs, and the experiencing on inner attitudes, feelings, and sentiments. Like a 
Así como cada lenguaje objetiva, categoriza, la realidad de una forma determinada y única, del mismo modo actúa la religión. Tener una fe religiosa se puede parecer bastante a lo que significa adquirir competencia lingüística en la gramática y recursos léxicos de una lengua ${ }^{17}$. Las religiones se conciben como diferentes idiomas para construir la realidad, expresar la experiencia y ordenar la vida ${ }^{18}$. Estamos ante una visión postliberal de la religión.

Lindbeck entiende que cada lenguaje lleva asociada una forma de vida y que conlleva un modo determinado de comprender la realidad ${ }^{19}$. La función de los contenidos doctrinales es, en este contexto, la de ser reglas comunitarias respecto al pensamiento, acciones y actitudes de quienes forman parte de dicha comunidad ${ }^{20}$. Su papel es similar al que desempeñan las reglas gramaticales respecto a un lenguaje. En ningún caso serán ni símbolos expresivos ni afirmaciones verdaderas, sino sólo reglas que, en caso de oposición entre algunas de ellas, basta con especificar cuándo se usan unas y cuándo otras ${ }^{21}$. Las doctrinas que posee cada religión pertenecen a un discurso de segundo orden respecto al lenguaje religioso, constituyen un metalenguaje del mismo ${ }^{22}$.

Si en lugar de tratar de lenguas consideramos culturas y pensamos las diferentes culturas como realidades que condicionan el pensamiento y la acción humana, que objetivan la realidad de una forma radical, entonces tenemos la otra imagen que plantea Lindbeck para entender lo que es una religión ${ }^{23}$.

\subsection{Consecuencias de la aproximación linguiístico cultural}

La visión de lo religioso que propone Lindbeck tiene una serie de consecuencias que él mismo expone.

culture or language, it is a communal phenomenon that shapes the subjectivities of individuals rather than being primarily a manifestation of those subjectivities" (ND 33).

17. Véase (ND 22). Lindbeck recoge el concepto de competencia clave en toda la lingüística generativo-transformacional a partir de Chomsky.

18. "In a cultural-linguistic outlook, religions are thought of primarily as different idioms for construing reality, expresing experience and ordering life" (ND 47-48).

19. (ND 17-18). Recoge las ideas del segundo Wittgenstein.

20. Las doctrinas son "comunally authoritative rules of discourse, attitude and action" (ND 18).

21: Este papel regulativo que desempeñan los credos lo retrotrae Lindbeck a la antigüedad cuando se habla de regulae fidei, véase (ND 18).

22. Las doctrinas "assert nothing either true or false about God and his relation to creatures, but only speak about such assertions" (ND 69).

23. Lindbeck asume la concepción de cultura y de religión que mantiene Geertz. 


\subsubsection{Superioridad explicativa del modelo linguíístico-cultural}

El autor destaca que su modelo es más explicativo que los otros dos. No obstante, aunque compare entre sí, por separado, las tres aproximaciones a la religión, va a poner el acento en la superioridad de su modelo frente a la teología católica postconciliar caracterizada por ser una mezcla de las dos primeras interpretaciones de lo religioso.

La teología postconciliar parte, en primer lugar, de una experiencia religiosa básica subyacente a todos los hombres y que aflora de diferente manera en las distintas religiones. Habría un sustrato religioso común. Sobre dicha base se recibe la revelación cristiana ${ }^{24}$. A este propósito recuerda Lindbeck la expresión de Tillich de la religión como substancia de la cultura y recalca que no es así. Una religión es como un esquema o marco conceptual (framework) linguiístico-cultural que conforma la totalidad de la vida y del pensamiento ${ }^{25}$. Lo hace de forma previa a la experiencia religiosa. Más claro, la experiencia religiosa viene determinada por cada una de las religiones concretas $^{26}$. La religión es vista como un fenómeno comunitario que condiciona las subjetividades de los individuos y no una manifestación previa a ellas ${ }^{27}$. Con la religión ocurre igual que con la realidad empírica, se ve desde el lenguaje, este nos permite categorizar la experiencia ${ }^{28}$. No es primero la expe-

24. Cita reiteradamente a Lonergan, por ejemplo en (ND 31-32).

25. "A kind of cultural and/or linguistic framework or medium that shapes the entirety of life and thought" (ND 33).

26. Véase (ND 32).

27. Véase (ND 33-34). No habría nada en común entre la experiencia de un Dios personal tal y como lo plantea el cristianismo y la experiencia budista de lo sagrado. ¿Por qué son experiencias radicalmente distintas para sus respectivos creyentes?, porque dichas experiencias vienen construidas por los mismos creyentes a partir de lo que dice su religión. Lindbeck toma esto por un hecho incontestable. Volveremos sobre el tema al estudiar el trasfondo teórico que late en las afirmaciones de Lindbeck.

28. Lindbeck recurre al conocido ejemplo de los colores, (ND 36-37). El estudio clásico es el de B. Berlin y P. Kay, Basic Color Terms (University of California Press: Los Ángeles 1969). Estudiaron los términos para denominar los colores en cerca de un centenar de lenguas y sus resultados dan pie, según algunos, a considerar el lenguaje como un medio radical para clasificar y conceptualizar nuestras experiencias. Los seres humanos poseemos un órgano visual -como otros muchos seres vivos- para distinguir los diversos colores a base de gradaciones de tono, luminosidad y saturación. Percibimos un "continuo del color". Pero, a diferencia de los animales poseemos el mecanismo que nos capacita para categorizar esos colores verbalmente, vemos colores determinados. En otros términos, ese continuo de color lo dividimos en diferentes puntos por medio del lenguaje. Así un español ve algo que es azul, rojo o amarillo, sin embargo algunos grupos de Nueva Guinea sólo ven en blanco y negro. Los límites conceptuales entre colores varían frecuentemente de un idioma a otro, con lo que surge el 
riencia y después la religión, sino justo al revés ${ }^{29}$. No puede haber una base experiencial común; así, el amor cristiano, el budista y la fraternité ilustrada son experiencias completamente diferentes ${ }^{30}$. Lo más que puede haber es cierto aire de parecido de familia. Los datos empíricos que proporciona el estudio de las diferentes religiones avalarían la visión lingüístico-cultural y no la expresivo-experiencial.

Si dejamos ahora los aspectos experienciales y pasamos a considerar los proposicionales, igualmente expone Lindbeck la superioridad de su modelo. Lo que el sujeto utiliza para estructurar todas las dimensiones de su existencia creyente no es, primariamente, un conjunto de proposiciones o enunciados verdaderos que son creídos, sino que es un conjunto de esquemas o historias (stories) ${ }^{31}$ que constituyen el medio en el cual el creyente se mueve. Dichos esquemas, narraciones o historias, asimilados por el individuo, se convierten, en la práctica, en un conjunto de habilidades o destrezas (skills) que le permiten organizarse la vida y desenvolverse en ella desde la fe ${ }^{32}$. Ser una persona creyente en una determinada religión equivale a interiorizar un conjunto de habilidades por práctica y entrenamiento ${ }^{33}$. Se aprende cómo sentir, actuar y pensar en conformidad con una determinada tradición religiosa del mismo modo que se aprende el idioma materno. El conocimiento primario que se adquiere de una religión no es acerca de ella, ni de lo que enseña, sino cómo ser creyente o miembro de esa religión en concreto, en la práctica ${ }^{34}$. En

problema de la traducibilidad. En su caso más extremo hay lenguajes que sólo tienen dos términos de color, blanco y negro, frente a lenguajes que poseen gran número de ellos. ¿Cómo traducir entre ambas lenguas? Esto puede desembocar en posturas relativistas radicales como la ya defendida por Sapir y Whorf en las décadas de los años 20 y 30: las distintas lenguas crearían mundos conceptuales profundamente distintos. Lindbeck cae dentro de esta órbita.

29. Véase ( $N D$ 34). La teoría determina la experiencia tal y como ocurre en la filosofía de la ciencia del Kuhn más clásico. Una religión es, en el fondo, como un paradigma científico. En un sentido más amplio podríamos decir que toda nuestra experiencia está predeterminada y con la religión no podría ser menos. Funciona como un apriori kantiano, véase ( $N D 33$ ).

30. Véase (ND 40). En el caso de la fraternité ilustrada, Gauchet saca conclusiones opuestas a las de Lindbeck, véase (Gauchet 1985).

31. Volveremos sobre este término en los comentarios. El concepto de historia (story) es clave en el pensamiento de Lindbeck.

32. "A comprehensive scheme or story used to structure all dimensions of existence is not primarily a set of propositions to be believed, but is rather the medium in which one moves, a set of skills that one employs in living one's life" (ND 35). Christian hablará de la religión como pattern of life (Christian 1987, 5).

33. "To become religious -no less than to become culturally or linguistically competentis to interiorize a set of skills by practice and training" (ND 35).

34. "The primary knowledge is not about the religion, nor that the religion teaches such and such, but rather how to be religious in such and such ways" (ND 35). 
el caso de la lengua materna no se memoriza un conjunto de reglas gramaticales sino que simplemente se aprende a hablar en el contacto con otros y se empieza a usar el lenguaje apropiado a cada circunstancia. Exactamente igual ocurre con la religión. La experiencia empírica avalaría igualmente esta superioridad del modelo lingüístico-cultural.

En esto último punto señalado, sólo en éste, coinciden la comprensión expresivo-experiencial y la lingüístico-cultural. Ambas recalcan que lo central para el creyente no es el credo de su religión objetivado en una serie de enunciados. Es mucho más explicativa, según Lindbeck, esta forma de entender las cosas que la que se describe en términos cognitivistas.

Hay otros aspectos que separan radicalmente la interpretación lingüístico-cultural de las otras dos. Hemos afirmado que, igual que el lenguaje categoriza la realidad en todas las facetas de la vida, también la posesión de un lenguaje religioso particular da una visión de lo sagrado previa a cualquier supuesta experiencia. Esta afirmación conlleva que una experiencia religiosa en solitario es imposible. Se da siempre la religión en conjunto con otros. No hay religiones privadas del mismo modo que no hay lenguajes privados. Lindbeck utiliza la idea de Wittgenstein de que los lenguajes privados son imposibles. Las experiencias religiosas son imposibles fuera de una religión que las enmarque y tales religiones son siempre colectivas ${ }^{35}$. Lo que sí puede ocurrir es que esa pertenencia, o mejor, el conocimiento de dicho lenguaje, no sea consciente sino sólo latente.

Si nos fijamos en cómo se produce la evolución en las religiones, en las innovaciones que se producen en las mismas con el paso del tiempo, éstas hay que entenderlas como producto de la interacción entre un sistema lingüísticocultural y las situaciones externas cambiantes. Cuando el esquema interpretativo religioso desarrolla anomalías en su aplicación en nuevos contextos, entonces se produce el cambio ${ }^{36}$.

\subsubsection{El problema de la verdad}

Obviamente a Lindbeck se le plantea el problema de la verdad. ¿Se puede aplicar el calificativo "verdadero" dentro de su forma de entender la religión? Las religiones hacen afirmaciones, ¿se puede decir que sus enuncia-

35. Véase (ND 38-39).

36. Lindbeck utiliza el término anomalía prácticamente en el mismo sentido en que lo utiliza Kuhn al estudiar el cambio científico. 
dos son verdaderos? Existen muchas religiones, ¿son todas igual de verdaderas? A solucionar este problema dedica el capítulo tercero del libro.

Cuando hablamos de lenguajes o de culturas no tienen ningún sentido el decir que uno es más verdadero que otro. Incluso dentro de una misma lengua, un juego de lenguaje wittgensteiniano no es más verdadero que otro. Sirven para cosas distintas. Ni siquiera se pueden comparar en la mayoría de las ocasiones. Lindbeck destaca el carácter de irrebasable que posee cada religión. Una religión tiene el carácter de entidad autónoma y cerrada. Las religiones poseen la propiedad de la insuperabilidad (unsurpassability).

Según la consideración cognitivista las religiones se pueden comparar utilizando la noción de verdad proposicional. Se trata de saber qué religión tiene más verdades. Una religión que estuviera completamente exenta del error y contuviera el conjunto de todas las verdades sería entonces absolutamente irrebasable (unsurpassable). Pudiera darse la situación de que una religión fuera más verdadera que otra caso de contener mayor número de verdades, o por tener menos errores. Tal religión resulta rebasada o superada por la primera. En este sentido se dice, por ejemplo, que la religión cristiana supera a la religión judía. La primera tiene la plenitud de la revelación y la segunda no.

Utilizando la visión expresivo-experiencial puede decirse que las religiones son más o menos eficaces a la hora de presentar y comunicar la experiencia interna de lo divino o incondicionado. En este aspecto las religiones son comparables, aunque no sean unas más verdaderas que otras. No obstante, el problema de comparar religiones empleando tal concepto es igual de difícil que el decidir sobre qué obra de arte produce mayor placer estético. Hay siempre gustos para todo.

En el caso de la consideración linguíístico-cultural de las religiones hay que hablar, en primer lugar, de adecuación categorial. Este concepto se aplica a la religión como totalidad y es previo a los criterios de verdad. Una religión es categorialmente verdadera si posee las categorías necesarias para hablar de lo que quiere hablar. Ocurre algo parecido a lo que sucede con los enunciados matemáticos dentro de un sistema, se necesita una serie de términos y de reglas para construir fórmulas bien formadas. Esto ocurre antes de tomar en cuenta cualquier realidad externa que haga los enunciados verdaderos pues puede que lo real permanezca desconocido ${ }^{37}$. Se trata de que los

37. Véase ( $N D$ 47-48). Más apropiado hubiera sido en este caso comparar lógicas diferentes. No sería más verdadera, como sistema lógico, una lógica bivalente que una trivalente. En el primer caso necesitamos los términos de verdadero y falso. En el segundo caso necesita- 
enunciados posean significado aunque no se pueda hablar de verdad proposicional, dado que ésta implica siempre una relación con una realidad externa al lenguaje. Puede darse que dos religiones posean términos absolutamente inconmensurables y no se puedan comparar ${ }^{38}$. Nos quedaríamos entonces sin decidir cuál de las dos es proposicionalmente verdadera aunque, categorialmente, sí puede resultar que las dos sean verdaderas ${ }^{39}$.

Respecto a la idea de verdad en la concepción linguiístico-cultural, ésta se mantiene en un sentido más fuerte que en la expresivo-experiencial, ya que bien pudiera ser que hubiera sólo una religión que tuviera los conceptos y categorías que la capacitan para referirse apropiadamente al objeto religioso y que las otras religiones fueran categorialmente falsas. Ello no impide que las demás religiones proposicional y expresivamente no fueran ni verdaderas ni falsas 40 .

Una vez establecida la noción previa de adecuación categorial de una religión como totalidad, pasamos a los enunciados de la misma. Deberíamos distinguir, en opinión de Lindbeck, entre verdad intrasistemática y verdad ontológica de los enunciados. Una cosa es la coherencia de los enunciados y otra la verdad proposicional de los mismos.

Una afirmación es verdadera, en el primer sentido, si es coherente con el resto de enunciados y con el género de vida a ella asociado. La verdad de entendimiento implica la verdad vital. Es un asunto que no lo resuelve la visión proposicionalista 41 .

mos tres términos. No podemos hacer lógica trivalente con sólo los términos verdadero y falso, si sólo poseemos estos dos nos faltaría adecuación categorial. Como se ve la riqueza de vocabulario es una condición previa a decir si determinados enunciados hechos en lógica trivalente son teoremas o no. Es cosa bien distinta estudiar la verdad o falsedad de enunciados ya bien formados dentro de los respectivos sistemas. Lindbeck pone el ejemplo de las matemáticas para recalcar que no se necesita realidad externa a la hora de hablar de la verdad. Más adelante se insistirá en esto al apostar por un concepto de verdad como coherencia intrasistemática. En mi opinión el ejemplo es poco afortunado pues posturas platónicas como las de Gödel hacen que el ejemplo de Lindbeck falle, aunque se vea perfectamente la intención que lleva. Lo que quiere decir está claro.

38. En el mismo sentido que habla Kuhn de inconmesurabilidad entre paradigmas científicos.

39. Lindbeck expone el ejemplo de los mapas. Dos mapas, si sirven para llegar al sitio adonde se quiere ir, entonces son categorial y proposicionalmente verdaderos independientemente de que estén a escalas diferentes o que uno sea más detallado que otro.

40. Véase (ND 49-51). Volveremos más tarde sobre el tema, es algo confuso.

41. Pone el ejemplo del grito de los cruzados, "¡Jesús es el Señor!", como el de un enunciado intrasistemáticamente falso. Tal enunciado no sería coherente, dados los comporta- 
Además, en segundo lugar, también podemos hablar de verdad ontológica, pero dicha característica sólo la adquieren los enunciados en virtud de una conformidad performativa del yo a Dios ${ }^{42}$. Dicho en otros términos, hablar de la verdad proposicional de los enunciados de fe supone que existe una correspondencia de la mente del sujeto a la realidad divina, es decir, que se da la fe 43. Con ello se deslinda la verdad ontológica de las expresiones religiosas de la que se produce en otros tipos de discurso tales como el científico. Para aquellas, la verdad es sólo una de las funciones que realizan dentro de su papel general de constituir una forma de vida. La verdad de tales proposiciones es sólo uno de los atributos de dichas proposiciones, atributo además que no puede considerarse únicamente en sí mismo, sino en correlación con todos los demás. En un discurso científico las expresiones no pueden funcionar a la vez performativa y proposicionalmente. Sin embargo en las expresiones religiosas no es así, la única forma de afirmar la verdad del enunciado "Jesús es el Señor" es hacer algo en relación a tal enunciado, es decir, comprometerse con lo afirmado en el enunciado 44. Esta manera de considerar la verdad de los enunciados es una nota distintiva de la consideración lingüístico-cultural de la religión 45.

Lindbeck recuerda que hay que distinguir entre oraciones (sentences) y proposiciones. La oración "Este coche es rojo" sólo pasa a ser proposición si se profiere cuando delante del que la dice hay un coche. Según sea el coche la proposición será verdadera o falsa. Si no existe tal coche, entonces no tenemos proposición y por lo tanto la oración no es verdadera ni falsa. Igual ocurre con las oraciones del lenguaje usado por una religión. Adquieren referencialidad sólo en determinadas situaciones muy concretas que implican el compromiso del creyente con lo expresado por la proposición. Tal es el caso, por ejemplo, que ocurre cuando se profiere "Jesús es el Señor" en la liturgia en un acto de adoración o de confesión de fe. Aquí sí podemos hablar de verdad ontológica, o de primer orden, de la proposición. La constitución de tal pro-

mientos a él asociados, con el resto de enunciados, ni con un género de vida cristiano. Para la visión cognitivista tal enunciado es verdadero sin más, pues efectivamente Jesús es el Señor.

42. Obviamente Lindbeck está utilizando los resultados de las propuestas sobre el lenguaje realizadas por Austin y Searle.

43. "A religious utterance, one might say, acquires the propositional truth of ontological correspondene only insofar as it is a performance, an act or deed, which helps create that correspondence" (ND 65). Volveremos sobre el tema más adelante.

44. "...that it is only through the performatory use of religious utterances that they acquire propositional force" (ND 66).

45. "...'performative-propositional' theological theory of religious truth that fits a cultural-linguistic approach" (ND 67). 
posición implica el compromiso de fe con ella. Sin embargo, para el proposicionalista, partidario de la visión cognitiva de lo religioso, es el lenguaje teológico y doctrinal el que es auténticamente proposicional. El defensor de la visión lingüístico-cultural piensa que la verdad o falsedad caracteriza sólo al lenguaje religioso ordinario tal y como es usado para amoldar la propia vida con las creencias en los momentos solemnes de celebración de lo religioso. Ahí se exhibe auténticamente la verdad o falsedad. Un compromiso inauténtico haría falsa la proposición. En cuanto a la teología y doctrina oficial de las iglesias, ésta no es más que un discurso de segundo orden, un metalenguaje, acerca de los usos de primer orden, intencionales, del lenguaje religioso. La teología es un metalenguaje que habla acerca de un lenguaje, no acerca de una realidad 46.

\subsubsection{Las doctrinas religiosas consideradas como reglas}

Dejemos el tema de la verdad y pasemos a otros problemas que plantean los credos y las doctrinas religiosas. ¿Cómo podemos justificar que las doctrinas no sólo sean normativas sino también permanentes a lo largo del tiempo? Normatividad, permanencia e infalibilidad, son aspectos que la teoría lingüístico-cultural también tiene que explicar.

Ya se ha dicho con anterioridad que, bien formalmente establecidas o informalmente aceptadas y operativas, las doctrinas son enseñanzas con autoridad y aceptación en la comunidad de creyentes respecto a lo que se debe creer y practicar. Las doctrinas delimitan lo esencial para la identidad y el bienestar del grupo en cuestión 47. Son imprescindibles, pues un grupo religioso no puede existir sin creencias ni prácticas distintivas que le identifiquen ante sí mismo y ante los demás. En este sentido expuesto es evidente que doctrina y teología son cosas diferentes. La visión proposicionalista tiene problemas a

46. "Technical theology and official doctrine, in contrast, are second-order discourse about the first-intentional uses of religious language. Here, in contrast to the common supposition, one rarely if ever succeeds in making affirmations with ontological import, but rather engages in explaining, defending, analyzing, and regulating the liturgical, kerygmatic, and ethical modes of speech and action within which such affirmations from time to time occur. Just as grammar by itself affirms nothing either true or false regarding the world in which language is used, but only about language, so theology and doctrine, to the extent that they are second-order activities, assert nothing either true or false about God and his relation to creatures, but only speach about such assertions" (ND 69). En ocasiones, cuando trata de las doctrinas, la teología se convierte en discurso de tercer orden.

47. "Church doctrines are communally authoritative teachings regarding beliefs and practices that are considered essential to the identity or welfare of the group in question" (ND 74). 
la hora de explicar qué son las doctrinas pues es difícil aclarar cómo en el curso del tiempo se desarrollan nuevas doctrinas y cómo otras se convierten en periféricas o son olvidadas. Algunas veces también ocurre que se reinterpretan las viejas doctrinas a nuevas situaciones. Temas como la evolución de los dogmas, la aceptación de dogmas nuevos, la pérdida de importancia o irrelevancia de antiguas formulaciones de fe son asuntos que debe explicar. Junto a ello está siempre latente la cuestión de cómo puede haber reconciliación entre iglesias con doctrinas contrapuestas, cómo armonizar los credos y no perder la propia identidad. Si todo lo relativo al cambio es el caballo de batalla de las posturas proposicionalistas, lo referido a la permanencia e infalibilidad es el problema de las posiciones expresivo-experienciales 48 .

En realidad, la corriente fundamental con la que hay que discutir aquí es la proposicionalista, pues las interpretaciones simbólico-expresivas se pueden descartar ya que consideran sin significado las calificaciones de incondicionalidad, irreversibilidad o infalibilidad dadas a las doctrinas. Tales posiciones no dejan nada para discutir 49. Pero eliminando el asunto no se resuelve el problema, pues la cuestión es que no explican el papel que de hecho tienen las doctrinas religiosas. Las doctrinas se tienen por los creyentes como incondicionales.

Lindbeck afirma que las doctrinas son reglas, pero ello no implica negar que también involucran proposiciones. Las reglas que formula el lingüista o el lógico expresan convicciones proposicionales acerca del lenguaje, sin embargo son de segundo orden y no afirman nada extralinguiístico. Para la teoría regulativa las doctrinas no son proposiciones de primer orden, sino de segundo orden. Son afirmaciones con pretensión de verdad intrasistemática, no ontológica 50. Desde la perspectiva lingüístico-cultural las doctrinas reflejan la gramática de la religión 51 .

Se puede hacer una primera clasificación de tales reglas dividiendo entre creencias acerca de lo que es ontológicamente verdadero -en el sentido ya expuesto-y doctrinas prácticas 52. Algunas de las doctrinas prácticas son nece-

48. (ND 78).

49. (ND 91).

50. (ND 80).

51. "From a cultural-linguistic perspective, it will be recalled, a religion is first of all a comprehensive interpretive medium or categorial framework within which one has certain kinds of experiences and makes certain kinds of affirmations. In the case of Christianity, the framework is supplied by the biblical narratives interrelated in certain specified ways (e.g., by Christ as center)" (ND 80).

52 . Véase para toda la clasificación ( $N D$ 84-88). 
sarias -esenciales-incondicionalmente 53. Otras son esenciales pero sólo condicionalmente 54 . Todas las incondicionalmente esenciales son permanentes 55 . Sin embargo las condicionales pueden ser permanentes o temporales 56. Las temporales a su vez se pueden clasificar en reversibles e irreversibles 57. Cabe también que haya doctrinas prácticas que no sean ni incondicionalmente necesarias, ni condicionalmente necesarias, sino sólo necesarias accidentalmente aunque permanentes en determinados casos 58 . El mismo esquema se aplicaría a las creencias tratadas como reglas 59.

Una vez expuesta su concepción de las doctrinas, Lindbeck intentará demostrar la validez de sus propuestas a la hora de interpretar, en concreto, los dogmas cristológicos, los dogmas marianos y la infalibilidad 60 . Respecto a los dogmas cristológicos hace ver que hay tres principios regulativos en el trasfondo de las afirmaciones dogmáticas concretas. Se trata del principio monoteísta: sólo hay un Dios; el principio de especificidad histórica: la historia de Jesús se refiere a un ser humano real y auténtico; el principio de maximalismo cristológico: todo lo máximo que se le pueda atribuir a Cristo se le atribuye siempre y cuando no se pongan en cuestión los otros dos principios. Estas tres reglas son los que están detrás y rigen la formación de los credos cristológicos. En función de ellas podrían variar, en principio, las formulaciones de los credos. Esto último no se va a dar, pues hoy en día un credo no es

53. Por ejemplo la "ley del amor" entre los cristianos. No puede darse dentro de la fe cristiana la situación en la que no se deba amar a Dios, o en la que haya que odiar al prójimo.

54. Lindbeck pone el ejemplo de no hacer la guerra. Otro caso pudiera ser "no matar", es una doctrina práctica esencial pero condicional. En determinadas situaciones -defensa propia- se mata.

55. La ley del amor es permanente.

56. "No matar" es permanente. Algunas afirmaciones de ética sexual podrían ser ejemplo de las segundas.

57. Un ejemplo de doctrina no necesaria incondicionalmente, temporal e irreversible es la condenación de la esclavitud. No se vio durante muchos siglos como doctrina, se adquirió con el paso del tiempo y ahora es una norma irreversible.

58. Son el tipo de reglas del estilo de conducir por la derecha o por la izquierda, que es completamente arbitrario elegir una $u$ otra, pero que una vez aceptada una de las dos ya no se pueden cambiar a no ser haciendo un trastorno desproporcionado. Lindbeck pone el ejemplo de los desarrollos litúrgicos postbíblicos de las navidades o la aceptación del primado del Papa.

59. Incondicional, necesaria y permanente es la afirmación "Jesucristo es el Hijo de Dios". Condicional, temporal y reversible es la creencia en la inmortalidad del alma pues está en función de la aceptación de una antropología previa sobre la cual no hay acuerdo. Condicionales, temporales, pero irreversibles son los dogmas marianos.

60. La aplicación práctica a estos casos concretos constituye el capítulo quinto del libro. Lo titula Testing the theory. 
importante tanto por su contenido dogmático, cuanto por su función litúrgica y expresiva: es vínculo de unión entre todos los creyentes independientemente de que les sea familiar lo que dicen. La autoridad que tienen los credos está, por tanto, en esos tres principios regulativos. Nicea y Calcedonia sólo son formulaciones históricamente condicionadas de doctrinas previas, reglas, incondicionales y necesarios. Formulaciones surgidas en el transcurso de la historia de la comunidad cristiana para proporcionarle identidad 61.

Dogmas marianos tales como la Inmaculada o la Asunción constituyen otra clase de problema. Son fruto de desarrollos muy tardíos. El primero de los dos citados es dependiente de una determinada interpretación de la doctrina del pecado original. El asunto a tratar será ver cómo la teoría regulativa anteriormente presentada puede explicar el surgimiento y la irreversibilidad de tal creencia. Podemos indicar a este efecto que, igual que ocurre en las lenguas, hay en las religiones doctrinas o consecuencias doctrinales que se descubren mucho más tarde 62. Sólo tras siglos de devoción popular y en combinación con cierta idea de lo que es el pecado original, junto con la conciencia del respeto de Dios por sus creaturas es como pudo formarse tal dogma. Los cristianos descubren que la gramática de su fe implica tal doctrina y, en este sentido, es irreversible. No obstante permanece el problema de qué sucedería si se cambiasen los presupuestos que han dado origen a tal dogma. Aparecería como doctrina reversible 63.

La infalibilidad plantea diferentes cuestiones. No es de las doctrinas, sino de las decisiones doctrinales de una comunidad o de sus maestros de las que se dice que son infalibles. Las doctrinas no son infalibles, sino que son irreformables. Podríamos comparar las definiciones doctrinales a decisiones acerca de la corrección o incorreción de determinados usos concretos del lenguaje. El lugar de la infalibilidad se sitúa en el conjunto de la comunidad de hablantes competentes de un lenguaje 64. Afirmar la infalibilidad es simplemente afirmar que la iglesia y/o su magisterio no quebranta la gramática de la fe en determinados asuntos. Del mismo modo, sería fácil interpretar el consensus fidelium o el consensus ecclesiae al modo que se hace en lingüística. Lo que consideran aceptable o inaceptable los hablantes nativos competentes en una lengua. De todas formas quedaría el problema de definir quiénes son "hablantes nativos com-

61. Véase sobre lo anterior ( $N D$ 92-96).

62. El teorema de completud de Gödel. Es una característica de los lenguajes de primer orden que se descubrió mucho después de estar trabajando con ellos. Además pertenece a la metalógica. Lindbeck cita a Gödel.

63. Véase (ND 96-98).

64. Para la infalibilidad ver (ND 98-104). 
petentes" 65 . En cualquier caso la pregunta a responder es siempre "¿qué es cristiano?”, y no “ ¿es verdadero el cristianismo?”. Dar respuesta a la segunda pregunta requiere por necesidad un compromiso existencial, lo que tradicionalmente se ha denominado fe sobrenatural. Por contra, a la hora de considerar las doctrinas y contestar la primera pregunta hay que ir a la práctica, a todo lo que hacen o no hacen los cristianos. Volviendo al equivalente lingüístico: el que uno sepa hablar su idioma materno sin esfuerzo no significa que necesariamente sea capaz de formular su gramática.

¿Ventajas de la concepción regulativa de las doctrinas sobre la proposicionalista? Parece que muchas. Quizá la discusión mayor estribe en que la visión regulativa hace a la proposicional superflua. Si las doctrinas pueden funcionar como reglas, qué necesidad hay de darles referencia ontológica. Lindbeck pone como ejemplo las teorías científicas. Las de Newton y Einstein sirven igual en determinadas circunstancias; aunque sean muy diferentes y la segunda supere a la primera, a lo mejor es preferible en algunos casos utilizar la de Newton. Del mismo modo en nuestro caso. El establecer qué teoría acerca de las doctrinas es mejor teológicamente depende de lo bien que organice los datos de la Escritura y de la Tradicción en vista a su uso en la vida y pastoral cristianas 66. Es decir, de cómo se comporte en la práctica. Si las doctrinas son pensadas como reglas, entonces la atención de los teólogos se concentrará en la vida concreta y en el lenguaje de la comunidad. Puesto que las doctrinas son mucho más para ser vividas que para ser interpretadas o reflexionadas, entonces no cabe duda que la visión regulativa es, en la práctica, muy superior a la proposicional.

\subsection{Hacia una teología postliberal}

Habitualmente se correlaciona la teología dogmática con la noción de fidelidad, la teología práctica con la de aplicabilidad y la teología fundamental con la de inteligibilidad. En el fondo las tres nociones están interrelacionadas 67. Una teología ha de ser -a la vez- fiel, aplicable e inteligible.

En primer lugar se considera que las afirmaciones de una teología han de ser fieles al depósito de la fe. La visión postliberal de la teología identifica

65. Más claro dicho: pudiera ser que un determinado giro lingüístico lo consideraran admisible sin más los hablantes nativos del castellano de una determinada región o clase social y no pensaran del mismo modo los académicos de la lengua.

66. "Which theory is theologically best depends on how well it organizes the data of Scripture and Tradition with a view to their use in Christian worship and life" (ND 106).

67. Véase (ND 112-113). 
fidelidad (faithfulness) con intratextualidad (intratextuality). Puesto que en opinión de Lindbeck el significado completo de una religión únicamente puede ser entendido en plenitud desde dentro, sólo valdrá -usando términos de Geertz- una descripción densa (thick description) de la misma. La teología debe tener en cuenta que una religión es una totalidad, es un medio interpretativo de la realidad donde todo se encuentra interrelacionado. Por ello, a la hora de estudiar los textos religiosos, la Escritura en nuestro caso, no habrá de olvidar que texto y forma de vida son interdependientes.

Así pues, no se puede atender exclusivamente a las formulaciones realizadas por medio del lenguaje de segundo nivel, a las doctrinas. El sentido ño puede ser extraño al texto, no es algo esotérico que nos sea revelado. No vale una posición referencialista, sino que el significado es lo que el mismo texto dice en términos de lenguaje comunitario. El texto no es más que una instanciación de dicho lenguaje comunitario 68. Hay que volver al texto en sí. En nuestro caso, la historia (story) de Jesús nos describe su identidad 69. Si nos fijamos en la Biblia en su conjunto, entonces se trata de describir a ese agente que es Dios, de ofrecer una descripción de identidad del mismo 70.

Para determinar el sentido de los textos son más importantes las consideraciones literarias que las histórico-críticas. Esta toma de postura, reconoce Lindbeck, choca con la tendencia liberal mayoritaria de intentar descubrir lo nuclear de la religión cristiana en esquemas externos al texto de la Es-

68. "The meaning must not be esoteric: not something behind, beneath, or in front of the text; not something that the text reveals, discloses, implies, or suggests to those with extraneous metaphysical, historical, or experiential interests. It must rather be what the text says in terms of the communal language of which the text is an instantiation" (ND 120).

69. "If the literary character of the story of Jesus, for example, is that of utilizing, as realistic narratives do, the interaction of purpose and circumstance to render the identity description of an agent, then it is Jesus' identity as thus rendered, not his historicity, existential significance, or metaphysical status, which is the literal and theologically controlling meaning of the tale. The implications of the story for determining the metaphysical status, or existential significance, or historical career of Jesus Christ may have varying degrees of theological importance, but they are not determinative. The believer, so an intratextual approach would maintain, is not told primarily to be conformed to a reconstructed Jesus of history (as Hans Küng maintains), nor to a metaphysical Christ of faith (as in much of the propositionalist tradition), nor to an abba experience of God (as for Schillebeeckx), nor to an agapeic way of being in the world (as for David Tracy), but he or she is rather to be conformed to the Jesus Christ depicted in the narrative. An intratextual reading tries to derive the interpretive framework that designates the theologically controlling sense from the literary structure of the text itself" (ND 120).

70. Todo lo anterior implica leer la escritura desde sí misma (scriptura sui ipsius interpres) según el esquema reformador, Lindbeck al poner el énfasis en la intratextualidad está siguiendo a Frei como después veremos, véase (ND 117-119). 
critura. La posición liberal ha llevado a realizar, cada vez, menos teología y a volcarse en la antropología, la historia y el estudio comparado de las religiones como formas de interpretar los textos de la religión 71. Esto ha llegado a convertir los textos en algo extraño para los creyentes. Ha resultado mucho mas fácil traducirlos a categorias externas que leerlos en su sentido intrínseco. Los textos así vistos se desnaturalizan. Hay que volver al estudio de los mismos como literatura, narraciones, historias (stories).

La teología intratextual reescribe la realidad dentro del marco de la Escritura, no traduce la Escritura a categorías externas a la misma. El texto es el que absorbe al mundo y no al revés 72. La verdad de una religión vendrá dada por su capacidad de absorber, por su poder asimilativo 73.

Además de por su fidelidad, las teologías son juzgadas por su aplicabilidad a la hora de marcarnos el camino a seguir. En un momento dado esto fue tarea de los profetas. En nuestros días el término se podría traducir por prospectiva (futurology) o sagacidad para descubrir los signos de los tiempos 74 . Los teólogos liberales parten de la experiencia humana y de la consideración del presente, ajustando desde ahí la interpretación del Reino de Dios en cuanto plenitud de las aspiraciones humanas presentes. Los postliberales, en principio, hacen justo lo opuesto. No construyen el futuro a partir del presente, manipulando de hecho tal futuro. Sino que hay que amoldarse a lo que el Reino de Dios es, tal y como nos lo narran los textos 75. Lindbeck reconoce que esta postura pudiera desembocar en un conservadurismo.

En tercer lugar nos queda la inteligibilidad, es decir, la presentación de los enunciados de fe como razonables. Tradicionalmente así se ha hecho. Bien entendido que no se trata de eliminar el misterio, sino de hacer ver que no son algo absurdo o contradictorio e, incluso, la razón podría intuir algunos aspectos previos a la misma formulación dogmática. Lindbeck interpreta ahora en diferente modo. La inteligibilidad ha de verse como destreza o habilidad $(s k i l l)$. Los postliberales son profundamente escépticos acerca del valor de la apologética. La gramática de una religión sólo se aprende, de verdad, como

71. Así es en el Jesus Seminar por ejemplo.

72. "Intratextual theology redescribes reality within the scriptural framework rather than translating scripture into extrascriptural categories. It is the text, so to speak, which absorbs the world, rather than the world the text" (ND 118).

73. "The reasonableness of a religion is largely a function of its assimilative powers, of its ability to provide an intelligible interpretation in its own terms of the varied situations and realities adherents encounter" ( $N D$ 131). Sobre este tema véase (Marshall 1990).

74. Lindbeck utiliza futurology, pero "futurología" en español tiene connotaciones quizá no aceptables en la intención del autor.

75 . Véase (ND 125-126). 
la gramática de una lengua: practicando. Sólo la práctica religiosa puede hacer inteligible una fe que, de hecho, es intraducible en categorías externas a la misma fe. La gramática de una religión, como la de cualquier lenguaje, no puede ser aprendida por un análisis externo a la experiencia de la misma, sino sólo por la práctica.

Lindbeck se decanta contra cualquier intento de fundamentación (foundation). Ahora bien, si con su opción se cae en el fideísmo o el relativismo, el coste puede ser demasiado alto. Recalca que no hay que identificar antifundacionalismo con irracionalismo. El no encontrar bases fuera de la misma fe viene del hecho de no poder describir las creencias al margen del propio lenguaje religioso, lenguaje que es una forma de vida. Si alguien no participa de esa forma de vida nunca entenderá tal lenguaje. No hay lenguaje exterior a la vivencia de la fe que nos permita describir con objetividad dicha fe. La inteligilidad de una religión se consigue con un buena práctica de la misma, con una ejecución (performance) aceptable. Con ello sitúa la razonabilidad de una religión como función de su fuerza asimiladora y de su capacidad de contagio. Se trata, en suma, de la habilidad que posea para proporcionar una interpretación de las diferentes situaciones y realidades que los creyentes encuentran a lo largo de su vida 76 .

La acción pastoral inspirada en la teología postliberal no consistirá en reescribir la fe con nuevos términos adaptados a la sociedad actual, sino en enseñar el lenguaje y prácticas de la religión a los posibles seguidores de la misma. Hoy las religiones tratan de acomodarse a la cultura, y es precisamente eso lo que no deben hacer. Ahora que la secularización acogota a las iglesias es el momento de formar comunidades que, sin rigideces tradicionalistas, inviten a aprender una nueva lengua y a actuar en consecuencia. Los métodos catequéticos seguidos en los años pasados no han resultado, ya que al intentar hacer creíble la fe, lo que han conseguido ha sido favorecer una traducción expresivo-experiencial de la misma que no da ningún fruto.

La teología tiene la misión de preparar para un futuro en el que la continua descristianización haga posible, aunque parezca lo contrario, una mayor autenticidad comunitaria. Estamos en este momento en una situación intermedia. De todas formas, el único modo de comprobar la validez de una teología postliberal serán los resultados. Si funciona en la práctica, entonces se convertirá en el modelo estándar de teología.

76. Véase (ND 131). 


\section{Trasfondo de las ideas de Lindbeck}

Para comprender con mayor precisión a Lindbeck hay que considerar un par de factores que están detrás de sus aportaciones. El primero de ellos es la teoría de la narrativa bíblica (biblical narrative), debida en su origen a Frei. El segundo factor, estrechamente ligado con el primero, es el ambiente intelectual en el que se desarrolla la obra de Lindbeck, la llamada Escuela de Yale.

\subsection{La biblical narrative}

Según el esquema de Lindbeck tendríamos un primer nivel del lenguaje religioso; en nuestro caso se trataría de la historia que cuenta el cristianismo, historia que viene narrada por la Escritura. Constituye el lenguaje natural que hablan los cristianos. Tal lenguaje natural posee una gramática. La gramática son las doctrinas o reglas que rigen dicho lenguaje. Sería el segundo nivel del lenguaje cristiano. Además podemos hacer una reflexión sobre la gramática, estaríamos entonces en el campo de la teología, constituiría el tercer nivel 77. Lindbeck se centra en el segundo y tercer aspecto y da por supuesto el primer nivel, el lenguaje natural cristiano. Pero su concepción de las doctrinas se apoya en cómo entiende tal lenguaje natural. Es aquí donde sigue las ideas de Frei.

El origen de la teología postliberal está ya en el pensamiento de Frei, colega por muchos años de Lindbeck en la misma universidad 78. Puede decirse que Frei puso las raíces del movimiento postliberal.

Frei elabora su pensamiento a partir de las ideas de un teórico de la literatura: Auerbach 79. Este autor utiliza el concepto de mímesis, o representación del mundo, para hacer un análisis del realismo en la literatura desde Homero a Joyce. El mundo que narra el texto es real en sí, no es alegoría de

77. La versión que da Kelsey es un poco diferente, véase (Kelsey 1990, 9-10).

78. Hans W. Frei (1922-1988). Nacido en Breslau y de ascendencia judía, aunque bautizado luterano, emigró a Estados Unidos en 1938 con su familia. Estudió teología y entró a formar parte de la iglesia episcopaliana. Toda su carrera académica, treinta años, la pasó como profesor en Yale. La biografía está recogida en (Frei 1993, 4-5). La introducción a dicho volumen (pp. 3-25), debida a Placher, resume su trayectoria intelectual. No publicó mucho, su obra fundamental es (Frei 1974). También (Frei 1975). Hay dos colecciones de artículos editadas póstumamente; son (Frei 1992) y (Frei 1993). Véase también (Ford 1996), como comentario a su obra puede consultarse el número monográfico de Modern Theology (AAVV 1992).

79. Erich Auerbach (1892-1957). Profesor de filología románica en Marburg, en 1936 emigró a Turquía y en 1948 a Estados Unidos donde impartió cursos en Yale desde 1950. Su obra principal es Mimesis: Dargestellte Wirklichkeit in der abendländischen Literatur (Bern 1942), traducida al inglés en 1953 y editada en español por primera vez en 1950 (Auerbach 1993). 
ningún otro, no tiene ni segundos significados ni enseñanzas encubiertas. El significado del texto está simplemente en lo que la historia (story) narra. Se distorsiona el significado de los textos si no se los ve realistamente, si no son considerados en sí mismos como narraciones. Así, por ejemplo, el significado de una novela de Dickens no es una enseñanza moral de cómo hay que comportarse con los huérfanos, ni tampoco es lo importante la información que nos proporciona acerca de cómo se vivía en la Inglaterra del siglo pasado. La historia (story) hay que verla como tal historia (story), con un significado en sí misma y no por referencias exteriores a ella. Un texto literario es, ante todo, texto.

El interés de Frei y, tras él, de Lindbeck será interpretar teológicamente la Biblia como Escritura, como texto. Mantiene que, durante los primeros diecisiete siglos de historia de la Iglesia, se leyó la Biblia como una narración (narrative) realista. La Biblia tenía ante todo un sentido literal y realista 80. No era comprendida como un escrito que nos trasmitiera una serie de doctrinas, ni tampoco se la consideraba como una obra edificante. Era ante todo una narración continuada, y eso a pesar de los numerosos géneros literarios que en ella se encuentran. Lo importante no era que hubiera una serie de verdades transmitidas por medio de los textos, ni que proporcionara modelos de comportamiento a seguir. Era, ante todo, una historia (story). Los cristianos vieron el mundo durante siglos tal y como estaba formado por la secuencia de historias (stories) bíblicas. Vivieron y sintieron un mundo así expuesto por los relatos bíblicos 81 .

Todo esto implicaba tres consecuencias. Primera: el sentido de la Escritura era literal. El que había que leer la Biblia literalmente era algo evidente e indiscutible hasta que el empirismo, el deísmo y la crítica histórica surgidos a partir del siglo XVIII propugnaron otra cosa. En segundo lugar: lo que contaba la Escritura había que enmarcarlo en un único mundo real e histórico y, además, en una única secuencia temporal. Era una historia continuada. En su conjunto la Escritura formaba una única narración. Por ello era muy sencillo ver el Nuevo Testamento como cumplimiento de promesas

80. "The words and sentences meant what they said, and because they did so they accurately described real events and real truths that were rightly put only in those terms and no others" (Frei 1974, 1).

81. "Christian preachers and theological commentators, Augustine the most notable among them, had envisioned the real world as formed by the sequence told by the biblical stories. That temporal world covered the span of ages from creation to the final consummation to come, and included the governance both of man's natural environment and of that secondary environment which we often think of as provided for man by himself and call 'history' or "culture"” (Frei 1974, 1). 
anunciadas en el Antiguo; del mismo modo que la figuración y la tipología eran algo consustancial a esta interpretación. Eran lógicas en ella. En tercer lugar: ese mundo único, formado por la combinación de todos los textos bíblicos en una única narración, era el único mundo real, o mejor, el mundo más real que todo lector, de cualquier tiempo o lugar, debía abrazar.

A partir de los siglos XVII y XVIII se produce una inflexión en el modo de leer la Escritura. Se empieza a localizar la Biblia en su mundo, y se considera su contenido como una serie de verdades acerca de Dios y del ser humano, verdades que hay que entresacar de los textos. A la vez se mira la Escritura como posible fuente de información histórica sobre el pasado. Se abre un abismo entre las historias narradas y la realidad que reflejan. Ambos mundos comenzaron a estar separados. El significado está ya fuera del texto. Es otra forma de leer la Biblia. Lo importante será ahora localizarla en un mundo histórico y considerarla como un conjunto de verdades acerca de Dios y de la naturaleza humana. Verdades que se encuentran más o menos escondidas en el texto. Además se piensa que por medio de los textos bíblicos se podrían adquirir enseñanzas sobre sucesos históricos. El mundo textual de las narraciones bíblicas se convierte en una fuente de información sobre el mundo.

Frei reclama que la Escritura vuelva a ser la guía normativa de la reflexión cristiana en un sentido que la Ilustración había hecho imposible. Aboga por una plain reading de la misma. Entiende el conjunto de la Biblia como una narración conexionada que genera su propio significado. Un significado que está al margen de la estricta referencia histórica. El género literario de la Biblia es el de narración realista 82.

Lindbeck, y con él todo el movimiento postliberal, recoge las ideas de Frei ${ }^{83}$. El sentido literal del texto tiene una prioridad informal para la comunidad cristiana. Además éste debería ser el contexto intelectual primario de un teólogo y no la presentación de la fe al mundo no creyente, tema que late en el subconsciente de los teólogos. No se debe considerar la Escritura, ni como fuente histórica sobre acontecimientos del pasado, ni como expresión simbólica de una serie de verdades que se puedan formular en forma independiente a ella. Los relatos bíblicos son narraciones, historias (stories), que constituyen el marco dentro del cual el cristiano comprende el mundo. $\mathrm{O}$

82. "A history-like fiction or fiction-like history to which the realistic modern novel also belongs" (Sykes 1989, 328). Ver también (Comstock 1986).

83. "While Frei was thinking about such matters, his colleague George Lindbeck was reading sociologists, anthropologists, and philosophers of science, and he concluded that what 
mejor, son el auténtico y verdadero mundo del cristiano. Con esta visión, Lindbeck se separa tanto de los métodos histórico-críticos como de otras formas que también entienden la Escritura como texto, pero que ponen el acento en el lector y en su historicidad. Tal es el caso de Ricoeur 84. Lindbeck ha resumido su posición en una frase ya citada y repetida por sus seguidores: el texto absorbe al mundo, y no al revés 85 .

Pongamos algún ejemplo para entenderlo mejor. Podemos imaginar el caso de Don Quijote: el mundo real en el que vive es el relatado por los libros de caballerías. Es un mundo de gigantes, caballeros y doncellas perseguidas. Para los que lo rodean, ese mundo no existe más que en los libros y en su imaginación, pero Don Quijote vive en dicho mundo y actúa como corresponde a esa vivencia. No es que crea en la existencia de gigantes, es que vive en un mundo de gigantes.

Si Don Quijote nos sirve de ejemplo, mucho más claro es, en mi opinión, el caso de Bastián en La historia interminable 86. Bastián encuentra un libro y se introduce en él por la lectura. Empieza a formar parte de una historia narrada. Su mundo deja de ser el de la escuela y el de la vida diaria para ser el mundo del libro. Vive dentro del libro. La narración (story) se convierte en su historia (history), en su vida. Al final vuelve de Fantasia y, de hecho, trae el agua de la vida consigo. Ya nada volverá a ser igual. El texto ha absorbido a Bastián.

Algo parecido ocurriría con el verdadero creyente que se introdujera, por ejemplo, en el Éxodo. No es el libro del Éxodo un modelo o una historia edificante de liberación. Sino que el verdadero creyente que lee el Éxodo entra a formar parte de esa historia de liberación. Una historia de imperios y de

Frei was saying made far more sense tham most contemporary discussions of theological method" (Placher 1989, 162).

84. "Postliberal theology attends to the biblical narratives as narratives rather than simply as historical sources or as symbolic expressions of truths which could be expressed nonnarratively. But unlike some other theologians interested in narrative, postliberals do not let the stories of our lives set the primary context for theology. They insist that the biblical narratives provide the framework within which Christians understand the world" (Placher 1994, 117). Hay que tener en cuenta que Frei recoge las ideas de Auerbach y, a su vez, se desmarca explícitamente de otros autores y tendencias que se han fijado en la Biblia como narración pero desde perspectivas muy diferentes. Es el caso de la narrative theology que sería, a los ojos de Frei, una versión moderna de las posturas liberales. Véase sobre lo anterior (Frei 1990b, 160-161), (Placher 1989, 123-138) y (Placher 1994a, 145). También se separa de Gadamer, para quien el significado de un texto emerge en la interacción entre texto e intérprete, no existe en un dominio ahistórico.

85. (ND 118).

86. Michael Ende, La historia interminable (Alfaguara: Madrid 1997, 44 reimpresión). 
esclavos, de mano de Dios y de portentos. Una historia que, ante todo, nos proporciona la identidad salvadora de Dios. Y no se descubre esa identidad porque el libro la describa, sino porque uno se encuentra con Dios personal y comunitariamente en la lectura del texto bíblico. Se siente el paso de Dios al lado de uno o de su propio pueblo 87. Ese es el auténtico mundo real al que uno entra a formar parte y no el de la vida diaria. Mejor, el auténtico creyente vive la vida diaria en pertenencia a ese mundo. Es absorbido por la narración. La muerte no hará más que dar la razón y mostrar que el mundo verdadero era el del texto. El creyente se queda para siempre en él 88.

Las parábolas de Jesús constituirían otro ejemplo claro. Narraciones que no pretenden ser ejemplos, historias ejemplares, alegorías. Sino que son historias que buscan la identificación del oyente con los personajes con vistas a formar parte de un mundo nuevo: el reino de Dios. Las narraciones de la pasión y de la resurrección también podrían leerse desde la misma óptica 89.

Hace veinte años Frei fue pionero en esta forma de leer la Escritura. El movimiento postliberal, con Lindbeck a la cabeza, ha recogido sus ideas 90 . Se considera la Biblia en términos literarios como una narración realista. Dado

87. En mi opinión, aunque parezca extraño, un caso típico de este tipo de lectura es el que hacen las comunidades neocatecumenales y las comunidades de movimientos de liberación. Les da de lado que la Biblia hable de un relato del éxodo, de dos o de catorce. Es completamente irrelevante que se pueda seguir un itinerario real o que sea todo fantasía. Lo único importante es la identificación de la vida personal y comunitaria -en un caso-, o de la historia del propio pueblo -en el segundo-, con la narración tal y como está. Al final del artículo volveremos sobre el tema.

88. No se trata simplemente de una verificación escatológica al estilo de la parábola de Hick. Los caminos del creyente y del increyente son distintos: "I would argue that a christian not only expects a different destination but also claims to see a different pattern in the road itself" (Placher 1989, 136, n. 11).

89. Véase (Placher 1994a). Los distintos acontecimiento narrados tienen su sentido dentro del texto, es irrelevante su historicidad. El caso de la tumba vacía sería un caso típico. El lector se encuentra con la tumba vacía como Bastián se encuentra con los límites de un mundo que se desmenuza. El creyente sabe que el Señor ha resucitado y vuelve a proclamar la salvación en Cristo. Bastián pone su empeño en la salvación de su mundo.

90. Véase (Lindbeck 1994): "Historical criticism does no better: it tells us, as is often said, what the bible meant, not what it means. Traditionalism and fundamentalism do not even try to meet the problem: they seek unchanging formulations, not the fresh words God utters here and now. For all these approaches, the sources are external to the reader rather than a language one learns to speak, a house or world within which one dwells.

It was not always thus. From the beginnings until well past the Reformation, Scripture was read as a Christ-centered and typologically unified whole with figural applications to all reality. Its world was for believers the truly real one within which they thought and lived both as individuals and communities. It was primarily a means for understanding other things rather than an object for study." (Lindbeck 1994, 266). 
que las historias son muy heterogéneas y que no toda la Biblia es narración, se presenta la posibilidad de enmarcar el conjunto de la misma como una narración que nos proporciona la identidad personal de Dios y de Jesús 91. De esta forma se interpreta la Escritura en términos teológicos como descripción de la identidad de Dios. Leyendo la historia uno aprende quién es Dios o quién es Jesús en el caso del nuevo testamento. Son narraciones que describen una identidad. Y, a fin de cuentas -piensan los autores- dados los resultados de la investigación sobre el Jesús histórico 92, no parece mala solución. Visto como narración llegamos a identificar cómo es Dios, o cómo es Jesús. Si nos fijamos en fragmentos históricos, entonces no llegamos a mucho, a casi nada para ser exactos. Además la Biblia, sus textos tal y como son, nos proporciona el mundo lingüístico que ha conformado la vida de la comunidad a lo largo de los siglos. Los fragmentos históricos no sirven para dar una identidad de grupo a la comunidad 93 .

\subsection{La Escuela de Yale. Los postliberales}

Dentro de las corrientes teológicas norteamericanas, el movimiento que hunde sus raíces en Frei y Lindbeck ha sido llamado Escuela de Yale 94 y, siguiendo la denominación usada por Lindbeck en el último capítulo de su libro, también ha sido catalogado de teología postliberal. Son los postliberales. En realidad la Escuela de Yale no es una escuela en sentido estricto, más bien se trata de un cierto aire de familia que comparte una serie de autores ligados, por docencia o por formación, a la Universidad de Yale. Este movimiento no es de ahora. El libro de Lindbeck ha servido para sistematizar y dar publicidad a una corriente que ya venía de lejos. Además ha tenido el acierto añadido de conseguir desatar la polémica en medios académicos como puede verse por la cantidad de bibliografía que existe sobre el tema. Hay quien ha dicho que parte del interés despertado por la obra de Lindbeck se debe, precisamente, a venir de Yale 95.

91. Un resumen bien claro de la postura de Frei se encuentra en (Hunsinger 1992, 124126, n. 13).

92. Y su culminación en el Jesus Seminar. Así Placher recoge la frase de Crossan: “... historical Jesus research is becoming something of a scholarly bad joke" (esto vale también para el campesino mediterráneo judío de Crossan). Véase cita en (Placher 1994a, 151). Sobre este tema véase el artículo de C. Mielgo en el número anterior de Estudio Agustiniano.

93. Véase (Placher 1994a, 158). Además de la biblical narrative, Frei se ha preocupado de los diferentes tipos de teología que se han hecho. Sus resultados tienen grandes semejanzas con los análisis de Lindbeck, véanse sobre todo (Frei 1992) y (Frei 1993).

94. Para una visión de conjunto de la Yale School, véase (Placher 1994).

95. Así (Placher 1985, 393) y (Michalson 1988, 109). En realidad el fundador sería Frei cuya obra, en mi opinión, tendría más relevancia que la de Lindbeck. 
¿Qué tiene Yale de particular? A la hora de ver el fenómeno religioso caben, a grandes líneas, dos posturas. Primera: pensar que hay una experiencia de lo sagrado, de lo incondicionado, común a todos los mortales. A partir de dicha experiencia básica, de ese magma indiferenciado de sentimientos, experiencias e inquietudes religiosos, se puede estudiar el cristianismo como una de las muchas construcciones habidas en la historia de la humanidad en respuesta a ese sustrato, respuesta que es más evolucionada que otras. Esta forma de ver las cosas, típica de siempre en la fenomenología e historia de las religiones europea, se introdujo en Estados Unidos gracias a los estudios sobre las religiones realizados por Mircea Eliade en la universidad de Chicago. Buscaba dar una introducción general a la religión como fenómeno universal 96. En la misma inspiración básica se movió el pensamiento de Tillich 97, que marcó de forma decisiva toda la teología norteamericana posterior.

Frente a la línea anterior -la de Chicago-cabe otra muy dispar, la que se siguió en Yale. La historia de las religiones es la historia de las comunidades religiosas concretas. Allí se estudiaron las tradiciones religiosas más como prácticas comunitarias que como expresiones de una experiencia común básica de lo religioso. La atención era puesta en cómo funcionaban realmente los textos religiosos en las comunidades y se centraron en un estudio pormenorizado de las religiones particulares. Los textos religiosos no se consideraban ni fuente histórica, ni símbolos de mitos universales. Al fijarse al detalle en religiones muy dispares cabe preguntarse si es que hay algo común a todas ellas. Es una pregunta legítima, por ejemplo, el cuestionar si hay algún punto

96. Mircea Eliade (1907-1986) fue profesor en Chicago desde que llegó a Estados Unidos en 1956 e impartió allí cursos hasta casi el final de su vida. Durante esta época, la tercera en el pensamiento de Eliade, se embarcó en un estudio histórico de las religiones e intentó mostrar la unidad fundamental de todos los fenómenos religiosos. Su Historia de las creencias y de las ideas religiosas comienza diciendo: "En historia de las religiones, toda manifestación de lo sagrado es importante. Todo rito, todo mito, toda creencia o figura divina refleja la experiencia de lo sagrado, y por ello mismo implica las nociones de ser, significación y de verdad". Eliade abogó por un estudio interdisciplinar del fenómeno religioso. La labor de Eliade además de intelectual fue divulgativa y organizativa. En gran parte gracias a la labor de Eliade se relanzó el estudio comparado de las religiones en Estados Unidos. Véase (Pals 1996, 158-197).

97. Paul Tillich estuvo en Estados Unidos desde 1933, en Nueva York sobre todo, después en Harvard y al final de sus días en Chicago (1962-1965). Siguiendo su método de correlación, Tillich interpreta los símbolos religiosos en referencia a cuestiones existenciales a las que intentan dar respuesta. La religión se define como autotrascendencia de la vida en la dimensión del espíritu, debe considerarse como una cualidad de las otras dos funciones del espíritu (moralidad y cultura) y no como una función independiente. Existe una dimensión de profundidad en todos los aspectos de la vida y "la polaridad de la libertad y del destino crea la posibilidad y la realidad de la vida que se trasciende a sí misma". Un amplio resumen de las ideas de Tillich sobre la religión puede verse en (Pastor 1997). 
común entre budismo y cristianismo, siendo primordial en la fe cristiana la experiencia de relación con un Dios personal y en el budismo no. Se recalcaron las oposiciones entre las religiones 98 . El representante clásico de la filosofía de la religión en Yale fue Christian ${ }^{99}$. Mucho más importante aún en esta forma de ver la cosas ha sido la obra de Geertz 100, que continúa la línea más clásica de la antropología norteamericana 101.

Para Geertz "una religión es: 1) un sistema de símbolos que obra para 2) establecer vigorosos, penetrantes y duraderos estados anímicos y motivaciones en los hombres 3 ) formulando concepciones de un orden general de existencia y 4) revistiendo estas concepciones con una aureola de efectividad tal que 5) los estados anímicos y motivaciones parezcan de un realismo único" 102. Determinar el papel social y psicológico de la religión es cuestión de comprender cómo las nociones que los hombres tienen de lo "realmente Real" y las disposiciones que tales nociones suscitan en ellos prestan color al

98. Véase para lo anterior (Placher 1994, 116). Dentro de estos nuevos planteamientos para la historia de las religiones, se consideraban las enseñanzas de Eliade y discípulos como teología encubierta. Hoy en día se da cada vez más una visión no teológica del fenómeno religioso, algo que ha sido paralelo a la expansión de los estudios de las religiones en las universidades civiles americanas, en departamentos de humanidades y al margen de las escuelas teológicas, véase (Lawson and McCauley 1993). Cuanto más laico es el estudio, menos notas comunes se encuentran entre las religiones. De todas formas el tema de la relación entre estudios de religión y teología sigue latiendo, véase (Neville 1993) y su crítica a la mentalidad postliberal.

99. William A. Christian, Sr. (1905-). Fue profesor en Yale hasta su jubilación. Una obra suya de 1972 se titulaba precisamente Oppositions of Religious Doctrines. Un análisis de los distintos niveles de doctrinas religiosas y de las funciones que desempeñan en las comunidades es (Christian 1987). Es mucho más pormenorizado que $N D$.

100. Clifford Geertz (1926-) estudió en Harvard con Talcott Parsons, que le influyó claramente: las personalidades individuales están conformadas y gobernadas por un sistema social que a su vez se encuentra controlado por un sistema cultural independiente. Junto a escritos etnográficos llevados al límite del detalle -descripción densa-; realiza una obra teórica que culmina en la recopilación de artículos publicada en 1973 -La interpretación de las culturas (Geertz 1987) - y que marca la antropología norteamericana de una manera determinante. De 1960 a 1970 fue profesor en Chicago y a partir de entonces en Princeton. Geertz reúne la condición de etnógrafo y de teórico de la antropología, véase (Pals 1996, 237-240).

101. Ya desde comienzos de siglo, la antropología norteamericana cobró un estilo peculiar frente a la inglesa y la continental. Mientras en Inglaterra y en el continente europeo se ponía el acento en el método comparativo -Eliade es heredero de ello-, en Estados Unidos se insistía en que sólo desde una rigurosa etnografía particular podía enraizarse una teoría general. Lo que importa es analizar la cultura detallada y particular de cada grupo étnico, quizás a partir de ahí se puedan sacar conclusiones generales. Además se puso el énfasis en la cultura como clave del estudio antropológico, es decir, en el sistema de ideas, costumbres, actitudes, símbolos e instituciones del cual la sociedad es sólo una parte. En la visión norteamericana, o de antropología cultural frente a la antropología social inglesa, se tendía a recalcar que el comportamiento individual es expresión de la cultura. A esta tradición se encuentra ligada la antropología simbólica de Geertz, véase (Pals 1996, 237-240).

102. Así en (Geertz 1987, 89). 
sentido que tienen de lo razonable, de lo práctico, de lo humano y de lo moral. Toda religión implica una visión del mundo y un ethos que se imbrican. Consiste en ideas y creencias acerca del mundo y en una inclinación a sentir y comportarse conforme a ellas. Pero Geertz insiste más en el ethos: en la conducta, valores, actitudes, estética... y menos en la visión del mundo. Pone el acento en la "personalidad de grupo" particular que crea cada religión. Se recrea en el detalle, en la estética y en el proceso de identificación que se produce en los rituales religiosos -por ejemplo en el balinés de Rangda y Barong- y se olvida de los mitos que están detrás. Rangda y Barong son presencias, su referencia se diluye; de hecho hay varios mitos diferentes que explican su procedencia, pero que no tienen importancia. Tales personajes crean identidad de grupo y se produce una identificación activa de los espectadores con ellos. Los mitos que están detrás son algo secundario 103.

Además de lo anterior no hay que olvidar los trabajos ya citados de Auerbach en teoría de la literatura que influyen decididamente en Frei. Con todo este bagaje, al que hay que sumar la filosofía de la ciencia de Kuhn, la filosofía del lenguaje de Wittgenstein y Ryle, las obras de sociólogos y antropólogos como Berger o Winch; profesores de diferentes disciplinas adquieren una serie de rasgos comunes en Yale. En lo teológico todos tienen sus raíces en Barth y en la obra de H. Richard Niebuhr, el gran teólogo en la historia de dicha universidad 104.

En los estudios bíblicos se percibe ese aire de familia, aunque con matices muy diferentes, en los dos biblistas famosos de Yale: Meeks y Childs. Ya desde finales de los setenta insistió Meeks 105 en aplicar un nuevo estilo a los estudios bíblicos tratando de describir el primer grupo cristiano igual que lo haría un sociólogo o antropólogo y salir, así, de una interpretación centrada ya en ideas teológicas abstractas (visión cognitivista), ya en una hermenéutica existencial (corriente expresivo-experiencial) 106. Se requiere una descripción densa microscópica del cristianismo primitivo 107.

103. Para lo anterior véase (Geertz 1987, 108-117) y la crítica de (Pals 1996). La teoría de Geertz está detrás de Lindbeck. No obstante pueden darse otras lecturas, para una lectura diferente de Geertz, véase (Power 1987).

104. H. Richard Niebuhr (1894-1962). Enseñó Teología y Ética en Yale desde 1931 a 1962. Véase (Ford 1994, II, 81-84) y (TRE 24, 468-479). El monoteísmo radical de H. R. Niebuhr y la absolutización de lo propio que conlleva, reformulado en términos comunitarios, puede seguirse en la obra de la teología postliberal.

105. Wayne A. Meeks, profesor de estudios religiosos en Yale.

106. "Se ha buscado en la historia social un antídoto contra las abstracciones de la historia de las ideas y contra el individualismo subjetivo de la hermenéutica existencial" (Meeks 1988, 13).

107. En la introducción de (Meeks 1988), original de 1983, se hace repetida mención de Geertz, aunque Meeks no parece identificarse del todo con sus planteamientos. La referencia 
Mucho más cercano a Lindbeck se encuentra Childs, que desde hace años defiende un replanteamiento en la lectura de la Escritura 108. Hay que describir la forma y función de la Biblia en su papel de Sagrada Escritura 109. La Biblia es ante todo Escritura con autoridad (authoritative Scripture) para la comunidad de fe, y continúa ejerciendo una coherción sobre el lector, limita el rango de las posibles interpretaciones. Es texto sagrado. En el tercer excurso que hace en su introducción al nuevo testamento clarifica mucho más las cosas 110, pues no se puede fundar la verdad bíblica sobre proposiciones objetivas y al margen de la recepción que se realiza en la fe y práctica cristiana 111. Comprender un texto implica ver como ha funcionado en el contexto de la comunidad que lo ha conservado, no en la de los exégetas suponiendo que formen alguna. El mismo canon establece el contexto de interpretación. Esta cercanía a Lindbeck no quita que le haga un par de críticas a la intratextuali-

a Lindbeck también es explícita: "dado que los modelos predominantes de religión están implícitos en el discurso religioso, la religión se formula siempre o bien en 'proposiciones cognitivas' o bien en 'expresiones de experiencia' como ha observado recientemente George Lindbeck. El propio Lindbeck, sin embargo, insta a los teólogos a adoptar un modelo 'lingüístico-cultural' similar al que se emplea en el presente libro" y, en nota, añade: "estas propuestas se hacen en un libro, aún sin publicar, titulado provisionalmente Theories of Religion and 'Method in Theology': An Encounter with the Thought of Bernard Lonergan. Lindbeck puso amablemente el manuscrito a disposición de sus estudiantes y colegas" (Meeks 1988, 20). Parece claro que se trata de $N D$. Por cierto, el título provisional es de lo más revelador respecto a las intenciones de Lindbeck. Volviendo a Meeks, en la introducción a (Meeks 1992), original de 1986, vuelve a repetir ideas citando a Geertz y Hauerwas entre otros.

108. "It was not a question of improving on a source analysis, of discovering some unrecognized new genre, or of bringing a redactional layer into sharper focus. Rather, the crucial issue turned on one's whole concept of the study of the Bible itself. I am now convinced that the relation between the historial critical study of the Bible and its theological use as religious literature within a community of faith and practice needs to be completely rethought" (Childs $1979,13)$.

109. "...to describe the form and function of the Hebrew Bible in its role as sacred scripture for Israel. It argues the case that the biblical literature has not been correctly understood or interpreted because its role as religious literature has not been correctly assessed" (Childs $1979,14)$.

110. "The canonical approach and the "new Yale Theology" (Childs 1984, 541-546). "Upon reflection it seemed to me that the profile of my proposal could be sharpened by responding to Lindbeck's book".

111. "Lindbeck's first category is helpful in showing that the heart of my canonical proposal has been missed when this conservative theory [neo-Evangelical Protestants] seeks to ground biblical truth on objective propositions apart from the reception by a community of Christian faith and practice", y continúa "I have also found Lindbeck's alternative proposal helpful in showing the significance of an intratextual context for a community of faith which seeks to render reality by its use of sacred texts." (Childs 1984, 543). 
dad y a la concepción de las doctrinas como reglas. Algo de contenido proposicional hay en la Escritura 112.

Meeks no da la impresión de encajar como postliberal, pero su método y los resultados logrados sí se adaptan muy bien al proyecto postliberal. Childs está mucho más cercano a pesar de algunas diferencias de perspectiva 113. Más postliberal es la obra de Kelsey que considera la autoridad de la Escritura en términos de sus funciones en la vida de las comunidades cristianas 114.

En mayor dependencia de Frei y con una relación más estrecha a Lindbeck se encuentran Hauerwas y Thiemann que se han ocupado, respectivamente, de la moral y de la teología fundamental.

Una perspectiva postliberal de la ética cristiana, paralela en el tiempo al trabajo de Lindbeck, es la que ha elaborado Hauerwas en diferentes obras 115. Es la communitarian ethics que trata de reafirmar la significación social de la Iglesia como sociedad diferente 116. Las normas éticas derivan de la gramática y ethos de las comunidades cristianas, no lo hacen de principios abstractos. El buscar universalidad y objetividad es un intento vano. Hay que abandonar la ilusión de un yo autónomo que pueda tener carácter fundamentador de las normas morales. Los principios morales cristianos sólo pueden entenderse desde las historias narradas en las que se originan. Estas historias dan coherencia a la vida 117. No se trata tanto de arreglar el mundo y sus problemas,

112. La crítica que hace a Brown refleja bien la posición de Childs: "By giving over the basic task of exegesis to the usual methods of historical criticism, Brown shatters the genuinely theological dimension of the text and effects a multiple reading which is reminiscent of the medieval church's appeal to the four senses of scripture with all its ensuing problems. In my judgment, the inability of Brown's method to deal adequately with the theological dimensions of the text emerges most clearly from his book on The Birth of the Messiah. In spite of impressive critical analysis the theological yield is small indeed and the separation between description and constructive theological exegesis is never overcome" (Childs 1984, 47).

113. En la conclusión volveré a hacer una breve referencia a este asunto.

114. David Kelsey, profesor de teología en Yale, su obra clásica es (Kelsey 1975). "To call a set of texts 'scripture' is, in part, to say that they ought so to be used in the common life of the church as to nurture and preserve her self-identity".

115. Stanley Hauerwas, estudió en Yale y es profesor ahora en la Duke University (Durham, North Carolina). Sus primeras obras son (Hauerwas 1981, 1983 y 1985). Una lista no completa de sus obras está en (Welch 1997). Para un resumen de su pensamiento véanse (Sykes 1989, 329-335) y (Ford 1994, 121-123). (Lauritzen 1987) analiza el papel que desempeña la narrativa en su obra, la idea de narrativa que defiende Hauerwas es algo diferente a la de Frei. También pueden verse (Milbank 1988) y (Jenson 1992).

116. "Thought this book touches on many issues it is dominated by one concern: to reassert the social significance of the church as a distinct society with an integrity peculiar to itself" (Hauerwas 1981, 1).

117. "For the service that Christians are called upon to provide does not have as its aim to make the world better, but to demonstrate that Jesus made possible a new world, a new 
cuanto de que las historias cristianas sirven para entendernos a nosotros mismos y al mundo en términos que hagan que los problemas aparezcan como insignificantes. Su concepto central es la noción de vida como don. La ética cristiana es fundamentalmente práctica y particularista. La ética ante todo es ética de la comunidad 118 , se requieren comunidades disciplinadas que den testimonio de ella. Es moral del grupo. Hauerwas pone especial énfasis en ir contra las pretensiones universalizadoras de Kant. La tarea de la ética cristiana no es establecer principios morales universales a partir de la ley natural o de alguna base antropológica común, sino llamar a los cristianos a preservar una comunidad que cuenta historias que manifiestan las virtudes cristianas y las hacen posibles 119 .

Thiemann se ha preocupado sobre todo de la teología de la revelación entendiendo ésta como promesa narrada 120 . La idea de promesa preserva la prioridad de la iniciativa de Dios, sabemos de ella por las narraciones de la Escritura. Rehúsa todo intento de fundamentar la teología sobre una intuición religiosa básica y común, o sobre cualquier tipo de doctrina revelada. Lo que tenemos en la Escritura es la narración de la identidad de Dios. Se trata de salvaguardar la iniciativa de Dios.

Así pues, la Escuela de Yale viene constituida por un conjunto de pensadores amplio y con una pluralidad de inquietudes. No son sólo Frei 121 y Lindbeck, hay más ${ }^{122}$. Característico de la escuela es el enfoque que da a lo religioso en general y a lo cristiano en particular. Si hubiera que definirlo en

social order" texto citado en (Lauritzen 1987,337). Uno de los puntos distintivos de Hauerwas es que adopta posturas pacifistas radicales. Insiste en el mensaje cristiano como una truthful narrative of non-violence, véase (Welch 1997, 82).

118. Ética de carácter comunitario, desde el cuál se juzga la ética de la liberación "rather Christians most important contribution to such struggles [for liberation] is to be a community of the liberated who can witness to paradigmatic forms of service" (Hauerwas 1986, 75). Hauerwas ha escrito este artículo en tono muy polémico contra la teología de la liberación, puede verse el estudio de (Kamitsuka 1997).

119. La narratividad en Hauerwas a veces parece más radical que en Frei: "The story that forms the church is... a reality-making claim that... tell us the truth about the world and ourselves" citado en (Jenson 1992, 289).

120. Ronald F. Thiemann, estudió en Yale, actualmente profesor en Harvard. Su obra clásica es (Thiemann 1985). Véase sobre él (Placher 1994), (Sykes 1989, 337-340), (Murphy and McClendon 1989, 207-208), (Oakes 1992) y (Goldberg 1988, 42-45).

121. Que, por cierto, parece que siempre rechazó la idea de una "Yale School”, véase (Frei 1992, x).

122. Además de los citados, tenemos a Charles Wood, William Werpehowski y James Buckley entre otros. Este último, católico, recuerda que no es una escuela propiamente dicha y que debe "deconstructing the myth of a Yale School" (Buckley 1992, xv). De todas formas el aire de familia no se lo quita nadie. 
unas pocas palabras diríamos: insistencia en la prioridad de la Escritura como texto y en lo peculiar de la comunidad cristiana como tal. En el sentido particular y distintivo de la misma.

\section{Comentarios críticos}

A continuación vamos a hacer una serie de comentarios a algunas de las propuestas de Lindbeck y de los teólogos postliberales.

\subsection{La biblical narrative}

Tanto Frei como Lindbeck admiten un punto de inflexión en la hermenéutica bíblica. Ya hemos expuesto que habría una primera etapa abarcando hasta el surgimiento de la modernidad, quizá incluso hasta un poco más tarde. A partir de ahí, de la Ilustración, se pierde la forma clásica de lectura de la Biblia. Si hasta entonces el texto absorbía al mundo, a partir de ahí es el mundo el que absorbe al texto. Ya sea que el "mundo divino" se convierta en el auténticamente importante y entonces los textos nos informan sobre tal mundo manifestando una serie de verdades sobre Dios y los hombres. O bien que sea el "mundo histórico" el que cobre importancia y entonces haya que descubrir por métodos histórico-críticos la auténtica realidad escondida o encubierta en los textos. $\mathrm{O}$, también, porque los textos son simbolizaciones de un "mundo humano" profundo, de unos anhelos de plenitud que se encuentran plasmados en él. En cualquiera de los tres casos el texto pierde la autorreferencia y adquiere una presunta referencia exterior. El texto pasa a describirnos una realidad ajena al mismo.

La teoría de la biblical narrative no es la única que se preocupa de la Escritura como narración ${ }^{123}$. Es una de las varias que hay, pero plantea pro-

123. El uso del término narrative es polifacético. En su relación con la religión habría distintos grupos que dan diferentes sentidos a la narrativa: "(1) a sacred biography group, largely historians of religion working on the lives of founders, saints and reformers and utilizing the vocabulary of the history and phenomenology of religion to interpret these narratives; (2) a faith development group, religious educators and psychologists of religion assessing biographical progression through six stages of religious development based on Piaget and Kohlberg; (3) a psychobiography group, psychologists of religion applying Erikson's life-cycle theory to biographies and autobiographies of religious individuals; (4) a character and community group, theological ehicists who use narratives, especially biographical ones, to guide character building, social criticism, and decision making; (5) a biblical narrative group, biblical scholars using a variety of methods to understand biblical narrative and its relation to nonbiblical narrative; (6) a myth and ritual group, literary critics, classicists, and some ancient Near East- 
blemas específicos. En mi opinión surgen con ella una serie de dificultades en cuanto a la consideración del texto, a su procedencia, contenido y relación con los lectores.

El primer problema brota al intentar encajar en una sola narración todo el texto bíblico. Frei y Lindbeck dan por hecho que sí es posible. Se asume que la Biblia narra la acción de Dios y nos proporciona su identidad, identidad de personaje claro está 124. En el caso del nuevo testamento se nos da la identidad de Jesucristo 125 . Indudablemente se puede optar por ello, el problema es si el precio del intento no es convertir al personaje principal, Dios, en esquizofrénico. Cualquier relato de narrativa histórica implica una coherencia interna de los personajes 126 . Incluir en una misma narración seguida la acción de Dios tal y como se supone en el libro de Nahum y en el Cantar de los Cantares, por citar dos casos, parece un poco difícil. ¿Cómo conjugar textos opuestos de la Biblia? ¿Qué ocurre con la ideología que plasman las narraciones? ${ }^{127}$. Además tal pretensión unitaria y totalizadora puede tener

tern specialists working on both ancient and modern narratives with a view to explicating their connections to ritual" (Grimes 1986, 1-2).

Según Oakes, la preocupación por las narraciones y el énfasis en la narrative theology se debe actualmente en la teología (la anglosajona) a diferentes razones: 1) Por ser el puente que tiene la teología con los estudios literarios y humanísticos para salir del ghetto académico. 2) Por su mayor aplicabilidad a las necesidades pastorales, dado que facilita la transición de las propuestas teológicas a la autobiografía y necesidades del creyente, éste sentido es justo el contrario a la intención de los postliberales. 3) Porque los aspectos narrativos de la Biblia son mucho más importantes para captar la identidad de la misma que otras ideas o conceptos usados tradicionalmente por la teología. 4) Además nos hace ver que la revelación no es un depósito heterónomo caído del cielo. Si la revelación se capta desde la narración, entonces puede dar sentido a la vida más fácilmente, véase (Oakes 1992, 39).

124. Al leer una novela histórica captamos las características, la identidad, de cada personaje. ¿Coincide tal identidad con la real de ese sujeto histórico? ¿Coincide la personalidad del Claudio de Graves con la del Claudio histórico? No lo sabemos con exactitud. Para Frei y Lindbeck la referencia que está detrás de los personajes bíblicos, cuando se da, es siempre una especie de noúmeno kantiano.

125. Hans Frei se ocupa de ello en (Frei 1975). Sigue a Ryle y afirma que una persona es lo que dice y hace. Esto hay que entenderlo en nuestro caso a partir de las narraciones. Conocemos de Jesús y de su carácter igual que aprendemos sobre un personaje en una novela, oyendo historias sobre él. No se requiere ni búsqueda de la historia, ni considerarlo como símbolo que encarne la experiencia humana. El momento crucial de la narración son los relatos de la resurrección.

126. Véase sobre esta dificultad (Goldberg 1988, 51-56). Estudia en concreto las aplicaciones de la narrativa en la obra de Thiemann.

127. La ideología patriarcal, por ejemplo, presente en gran parte de la Escritura y que la teología feminista ha denunciado, véase (Placher 1994a, 144). Este tema lo ha tratado especialmente Sallie McFague, véanse los comentarios de (Reynolds 1997). 
una carga ideológica muy grande, dejando de lado relatos minoritarios más subversivos. Una solución sería afirmar que la personalidad de Dios está fuera de nuestros encasillamientos, es contradictoria, más allá de nuestra lógica. Tal postura no haría sino reforzar tal impresión esquizoide 128.

Frei parece decir que la comunidad cristiana es la que da las reglas de interpretación, pero tales reglas estarían entonces por encima del texto y, si no salen del texto, ¿en dónde se apoyan? ${ }^{129}$. Son algo previo al mismo. De hecho, la opción de Lindbeck y Frei da el mismo valor a toda la Escritura y no pretende, en ningún caso, armonizar las contradicciones internas de la misma 130. La dejan tal y como está, y sin dar preferencia a unos textos sobre otros. ¿Es correcta tal opción teológica? ¿Tienen el mismo valor todos los textos? Dar un valor preferencial a algunos pasajes equivaldría a hacer intervenir al lector, individual o comunitario, que es el que escoge unos y deja de lado otros. Supondría hacer intervenir factores externos en la interpretación del texto. En cierto modo sometería la Escritura al juicio del lector. Esta postura es válida en otras interpretaciones narrativas de la Escritura 131, en Frei y Lindbeck no.

Además, el texto no es un absoluto en sí, no viene de la nada. Desde la sola scriptura protestante de Frei y Lindbeck parece que se toma el texto como un incondicionado 132, pero éste tiene una génesis, alguien lo ha escrito. Y ese alguien, desde luego, no es Dios. La idea de Lindbeck y Frei sobre la Biblia da la impresión, a veces, que se acerca más a lo que es el Corán, reve-

128. A no ser que le demos una identidad al protagonista parecida a la que tienen algunos personajes de Alicia en el país de las maravillas.

129. Así la confesión de fe cristológica debería controlar la lectura del texto. En ese caso estamos antes del texto, o fuera del mismo. "The logic of the primary community rule for reading entails the background belief that Scripture is a response to God's initiative" (Sykes 1989, 328-329).

130. Ningún tipo de Diatessaron. Placher recuerda este tema (Placher 1994a, 145).

131. Por ejemplo en la que sigue a Ricoeur y que adoptan otros teólogos. En opinión de Ricoeur hay que considerar la relación que se produce en todo texto entre referencia, significado, imaginación y tiempo. Pertenecemos a la historia antes de contar historias o de escribir la historia. El texto es el medio por el que nos comprendemos y la comprensión implica simultáneamente apropiación y distanciación. Para la facción de teólogos narrativos que dependen de Ricoeur, la narración es inherentemente impura en sí misma porque ésta tiene siempre una pretensión referencial más o menos escondida, véase (Oakes 1992, 44-45). Un resumen del pensamiento de Ricoeur puede verse en (López Sáenz 1997) y una excelente exposición la da (Comstock 1986) que aboga por un narrativismo impuro en el que hay que considerar siempre el problema de la verdad. Ya hemos citado anteriormente la crítica de Frei a estas corrientes hermenéuticas.

132. "The text indeed becomes a kind of sacred object, an incarnation of meaning" (Sykes 1989, 328). 
laciones recibidas por Mahoma, que a otra cosa 133. Esta no es la situación de los textos cristianos escritos por alguien, por muchos, de carne y hueso. Escritos alguna vez, en algún lugar y, sobre todo, escritos por algún motivo.

Otro tipo de problemas es el referente a la lectura del texto. Habrían tenido lugar a lo largo de la historia dos formas de lectura de la Biblia. La primera de ellas es la añorada por Frei y Lindbeck. Ahora bien, son dos formas de lectura del texto porque responden a dos sociedades y a dos racionalidades diferentes. Cada una está en consonancia a una sociedad y a una racionalidad. Aquí sí se puede ver la conexión lectura-mundo de vida. No es que con la modernidad y la ilustración cambien las pautas de lectura, es que cambian la situación del ser humano ante el mundo. La primera forma de lectura responde a un modo de ser en el mundo, la segunda a otro completamente diferente 134. Son racionalidades diferentes. Un campesino medieval puede oír hablar de ángeles, diluvios, mitos y milagros; a fin de cuentas él vive en un mundo de dragones, filtros, quimeras y alquimia 135. Hay una coherencia entre modo de ser en el mundo y lectura del texto bíblico. El tipo de lectura responde a un tipo de racionalidad o forma de situarse ante toda la realidad. Entrecruzar forma de lectura premoderna con forma de vida moderna lo que conlleva, de nuevo, es el riesgo de esquizofrenia. Esta vez en el lector.

No sólo la manera de situarse ante el mundo es diferente, sino que la cosmovisión social premoderna es bíblica. Se está en una sociedad cristiana. Desde la ilustración hay que dar razón de la fe, y por lo tanto de los textos, en una sociedad paulatinamente no cristiana, no bíblica. El texto como tal es público, intersubjetivo. Es texto para todos, con una objetividad, de ahí que quepa observarlo desde diferentes perspectivas: la del antropólogo, sociólogo, historiador... Si en un primer momento coinciden armónicamente la racionalidad del lector, la sociedad y lo que el texto narra, entonces la primera clase de lectura es lógica. No hay ningún desfase. Si la racionalidad del lector y la sociedad están en otra órbita a la del texto, lógicamente se producirá otro posicionamiento ante el texto, otra manera de leer la Escritura 136.

Es con una razón intersubjetiva, secularizada y científica, compartida por creyentes y no creyentes, y acorde con toda una cultura, con la que se lee el texto 137. También antes todos poseían una misma racionalidad premoderna.

133. O a la de Bastián que se encuentra con el libro por azar.

134. Fruto de una evolución a partir de la primera según la tesis de Gauchet.

135. Una amplia exposición en (Giordano 1995).

136. Con lo cual habría que dar la razón a las propuestas de Ricoeur o a las de otros autores tales como los pertenecientes a la corriente que insiste en la estética de la recepción.

137. Racionalidad sobradamente descrita por Apel y Habermas. 
Intentar cruces diferentes puede crear disfuncionalidades que lleven a situaciones como la de que programadores informáticos se suiciden, siguiendo palabras reveladas, para subir a un cometa 138.

Un asunto diferente es el análisis de textos concretos desde la perspectiva de la narrativa bíblica. Puede haber factores muy positivos, por ejemplo, en el estudio de las narraciones de la pasión y resurrección. El mismo Tracy, tan crítico con los postliberales en otros aspectos, reconoce que esa narración concreta tiene en sí algo que sólo se capta con una lectura seguida de la narración como tal 139. Es insustituible para proporcionar la identidad del protagonista. Aquí sí que la narración, sobre todo si es leída en un contexto litúrgico solemne, absorbe al lector. De todas formas es sólo una de las posibles lecturas.

La propuesta de Frei y Lindbeck nos hace perder el problema de la verdad de los textos. Sólo importaría el significado de los mismos, carecerían de referencia 140 , con lo cual surge el problema de la revelación. ¿Hay algo más allá de la story? ¿O es la historia bíblica un fin en sí misma? La Escritura nos despliega la realidad de la obra creadora y liberadora de Dios en el mundo, por lo tanto el significado de la Escritura sobrepasa su particularidad cultural 141. ¿Es justificable el reduccionismo postliberal? 142.

138. O la de ingenieros que no admitan transfusiones de sangre para sus hijos. Los casos son múltiples. Se podrían poner otros más directos.

139. "Any Christian theology which confesses its faith in the presence of Jesus Christ (...) will always need the plain sense of these narratives to achieve what neither symbol alone, nor doctrine alone, nor historical-critical reconstruction of the original apostolic witness alone, nor conceptual theology alone, nor confession alone, can achieve: a theological clarification of how the reality of Christ's presence is manifested through the identity of that Jesus rendered in the realistic, history-like narrative of the passion and resurrection, a narrative-confession of this one unsubstitutable Jesus of Nazareth who is the Christ of God" (Tracy 1990, 42).

140. Dicho en términos de filosofía del lenguaje: sólo cabría una teoría del significado y no una teoría de la referencia.

141. Para el problema de la revelación véase (Wiedenhofer 1988, 49). También la crítica de (Wilson 1994, 409): “... the Gospel establishes and reveals an everlasting reality. If this es true, then continuity in the faith depends upon the continuing reality of God's work in the world. The 'story' identifies that reality and even participates in that reality, but the story of past events is not the fundamental locus of continuity. Instead, the fundamental locus of continuity is the everlasting actuality of the creative-redemptive work of God. In this view, it is not the text that absorbs the world, but the kingdom that redeems creation. In this view, faithfulness is not our achievement of a particular interpretation of the world, but our participation in the work of God. In this view, the story of God is not lagging behind culture, waiting for Christian interpreters to update it; rather, the story of God is always ahead of us, awaiting our participation".

142. Comstock ha señalado que el problema de la teología narrativa estriba en qué busca: el significado o la verdad. 
No es lícito admitir que la fe sólo pueda hacerse inteligible en un modo no teorético, no proposicional. Puede que exista la tentación, fácil, de olvidarse de la referencia de los textos y del problema de la verdad de los mismos 143. Es manifestación, quizá, de un temor al debate abierto. Plasmaría el deseo de encerrarse en sí mismo y la idea de que la apologética no tiene ninguna salida 144. La fe no tendría nada que hacer con la racionalidad contemporánea 145.

Sin embargo, explicar el texto nunca ha sido algo superfluo en la historia de la Iglesia. Es más, no hay texto si no hay lector, y es la consideración histórica, sociológica etc. del texto la que permite que el lector considere lo narrado como algo que pertenece al mismo mundo que él, y por lo tanto válido para él. El mundo en que se introduce Bastián es un mundo radicalmente diferente al suyo, él tiene que olvidarse de su mundo e introducirse en algo completamente ajeno. El único punto de contacto entre ambos mundos es el libro. Bastián va a otro mundo. La oferta de Dios en Cristo es para nosotros y para nuestro mundo. No tenemos que olvidarnos de nuestro mundo para entrar en otro, sino que se nos promete la plenificación de lo que somos, creación de Dios. Dios no abandona a esta su creación, la plenifica en Cristo. No es lo nuestro tan malo como para que sea necesario olvidarse, salir de ello y entrar en algo ajeno. El texto bíblico atañe a este mundo, precisamente por eso el ver desde la crítica histórica los textos nos permite considerarlos como nuestros y lo que se dice en ellos tan humano como nosotros. Ver la historia en la historia (story) es ver nuestra historia, o mejor, ver el mensaje de salvación en nuestra historia y hecho con nuestra historia para nosotros. Los métodos histórico críticos, sociológicos etc. tienen así, en sí mismos, valor teológico 146. Nos hacen ver que es nuestra Escritura 147.

143. "It is, I believe, the pathos of much of narrative theology that it too easily tries to finesse these issues by a retreat into a mere act of recital, meant for the sustenance and benefit of the believing community, rather than going outward and facing the hard issues of preaching to a world that can raise objections to the Christian message almost at every point" (Oakes 1992, 58).

144. Véase (Oakes 1992, 49-51).

145. Con lo que sale perdiendo la fe. Volveremos después sobre el tema.

146. Aunque siempre cabe una lectura ambivalente. Los estudios bíblicos hechos con ojos de antropólogo o sociólogo, Meeks por ejemplo, ¿no llevan a añorar esa pequeña secta cristiana, o conjunto de ellas -que no está muy claro al principio-, perdida en el Imperio? Tras los estudios de sociología del cristianismo primitivo y después de ver la mezcolanza de creencias, influencias culturales y variedades de tipos de comunidades, ¿no queda en los postliberales una idealización de la conciencia de identidad grupal y del sentido de pertenencia personal a la misma? La comunidad de Corinto tendría muchos problemas, estaría al borde del caos, pero era la comunidad de Corinto. Enfrentados, pero el mismo enfrentamiento producía identidad. Lo más opuesto a la religiosidad light del magma cristiano actual. Digamos que dichos estudios sociológicos tienen un efecto rebote un tanto curioso.

147. Sería preferible por lo tanto un dirty intratextualism en el cual el texto es formado en una conversación entre pastoral, tradición y vida personal, es decir un contextualismo, ver 


\subsection{La alternativa lingüístico-cultural}

En relación a las propuestas concretas de Lindbeck también pueden hacerse una serie de comentarios críticos.

\subsubsection{Las doctrinas religiosas}

Como ya ha quedado suficientemente dicho, Lindbeck se propone tratar el problema de cuál es la naturaleza de las doctrinas religiosas, pero después de leer el libro no se sabe muy bien qué se entiende por doctrina. No considera que la doctrina sea el conjunto mínimo de creencias que podrían definir una religión, el credo estricto expresado en una serie de enunciados, sino que Lindbeck se refiere a un conjunto en sentido mucho más amplio, a todo lo sostenido dentro de una religión y formulado, parte en enunciados, parte en otro tipo de oraciones.

Constituirían, por tanto, ejemplos de doctrina católica afirmaciones tales como "Jesucristo es el Hijo de Dios", "Hay que amar al prójimo como a uno mismo" e incluso, en un sentido más laxo, podríamos incluir como doctrina creencias del tipo "María santísima vino en carne mortal a Zaragoza"... Lindbeck nunca acota de modo preciso qué entiende por doctrina. Aquí asumiremos que todo lo contenido en el Catecismo de la Iglesia Católica constituiría para Lindbeck el conjunto de la doctrina católica. No debemos olvidar que lo típico de las doctrinas es que son normas de creencia comunitaria y de acción.

$\mathrm{Al}$ interpretar Lindbeck así las doctrinas en cierto modo se pierde, pues no son todas igual de definitorias a la vez. Efectivamente él hace una catalogación de creencias, pero es una clasificación diacrónica. Unas son necesarias siempre, otras tienen una necesidad condicional pues se pueden cambiar. El problema es realizar el análisis sincrónicamente porque, en un momento determinado de la historia, hay doctrinas que dentro de la misma comunidad religiosa unos las ven como imprescindibles y otros las consideran completamente superfluas, o mejor, ni siquiera las consideran doctrinas en absoluto. Hay una gradación de importancia entre las doctrinas. Con ello todo lo más

los comentarios críticos de (Buckley 1990). En otro orden de cosas, algunos críticos han destacado que el análisis de Lindbeck sólo vale para las religiones del libro. No se puede hacer una teoría general de la religión desde esa perspectiva, véase (Lawson and McCauley 1993) que, además, abogan por un concepto de sistema religioso como sistema de conocimiento compartido que está cognitivamente representado en las mentes de los participantes. 
que se podría decir es que hay un núcleo de doctrina que define a una religión y luego hay otra serie de doctrinas aceptados por unos y rechazadas por otros que no intervienen en la definición de la pertenencia a la comunidad 148.

Además se comparten unas determinadas doctrinas por todos, pero prácticamente sólo en su formulación lingüística. No tendríamos más que un mínimo núcleo común y definitorio. Dentro del mismo idioma se dan dialectos muy diferentes, prácticamente hasta hacer la comprensión mutua casi ininteligible ${ }^{149}$. De ahí que la interpretación de Lindbeck tenga sus pegas. Dentro de una misma religión se dan lenguajes muy diferentes.

Esto es algo muy característico del cristianismo y que no se da en las religiones estudiadas por los antropólogos, religiones minoritarias perfectamente integradas en una cultura como un todo. Curiosamente, cuanto más integrado esté el cristianismo en la cultura occidental contemporánea, más posible es que se dé el fenómeno del pluralismo, pues una de las características de la racionalidad contemporánea es la pluralidad de visiones y perspectivas en la consideración del sentido. Aquí la consideración de la religión como cultura va contra la tesis de Lindbeck. Él inconscientemente piensa, al hablar de cultura, en la de los nuer, los bosquimanos o los achual. ¿Por qué no piensa en la cultura occidental contemporánea? ${ }^{150}$.

148. El creer que "Jesucristo resucitó" define a todos los cristianos, el amor al prójimo también. Creer en determinadas apariciones o el seguir determinadas pautas de comportamiento sexual no son definitorios en absoluto.

149. Esto ocurre con el lenguaje de forma habitual. Los hablantes del español se entienden en determinados niveles. Por ejemplo, al ver un telediario en un país de habla hispana cualquier hisponablante, independientemente de su procedencia, lo entiende. Pero un español hablando en la jerga de los suburbios de Madrid y un mestizo ribereño del Amazonas hablando en su español particular lo más probable es que no se entiendan. La liturgia oficial de la eucaristía muestra un lenguaje cristiano común. ¿Pero es común el lenguaje cristiano de una comunidad de base brasileña y el de una comunidad neocatecumenal polaca? ¿Y el de una cristiana feminista norteamericana es igual al de una monja clarisa? ¿O los de Casaldáliga o Gaillot iguales a los de un funcionario curial? Tan comunidad es una como otra e igual de obispos son todos. Forman parte de la misma Iglesia pero hablan dialectos muy diferentes. ¿Son los significados de los términos usados los mismos?

150. Otro tema, en el que no vamos a entrar, es el problema de la inculturación. El cristianismo ha sido capaz de asimilar situaciones y mundos de lo más dispares: cultura grecolatina, germánica, china... Da la impresión de que la mentalidad occidental, racional, técnica y democrática se le ha indigestado. En su momento se hizo judío con los judíos y griego con los griegos, ¿y ahora? 


\subsubsection{Las doctrinas religiosas son reglas}

Lindbeck no sólo es confuso en la delimitación de las doctrinas, sino también en la consideración de su papel 151. Afirma que las doctrinas no forman parte del discurso de primer orden, del lenguaje, de una religión; sino que son de segundo orden, forman el metalenguaje o gramática de la misma 152. Las doctrinas no tratan directamente acerca de Dios o de la humanidad, sino del hablar de la Iglesia acerca de Dios o de la humanidad. En este sentido son

151. Ya la misma clasificación tripartita que hace Lindbeck no es tan clara y ha sido discutida por (Behrens 1994, 399-402). Caben diferentes lecturas de sus propuestas:

1. Una primera presentación podría ser:

a) Teoría proposicionalista (P1): los enunciados doctrinales expresan, necesariamente, pretensiones de verdad y tienen, necesariamente, valores de verdad. Cada uno de los enunciados religiosos o es verdadero o es falso.

b) Teoría expresivo-experiencial (EE1): los enunciados doctrinales expresan, necesariamente, experiencias o estados mentales.

c) Teoría regulativa (R1): los enunciados doctrinales prescriben reglas de uso del lenguaje religioso.

Cada una de estas tres interpretaciones admite una consideración inclusiva o exclusiva. La exclusiva implica que la asunción de una de las tres implica la falsedad de las otras dos. En la consideración inclusiva la verdad de una teoría no implica la falsedad de las otras. Lindbeck parece ser exclusivista.

2. Un segundo modelo sería el siguiente:

a) Teoría proposicionalista (P2): los enunciados doctrinales expresan pretensiones de verdad acerca de objetos externos no mentales, ni linguiísticos, es decir acerca de Dios y del mundo.

b) Teoría expresivo-experiencial (EE2): los enunciados doctrinales expresan pretensiones de verdad acerca de experiencias $\mathrm{u}$ otros estados mentales.

c) Teoría regulativa (R2): los enunciados doctrinales expresan pretensiones de verdad acerca del lenguaje religioso.

También en este caso puede haber una versión exclusiva y otra inclusiva.

P2 es más fuerte que P1, P2 implica P1 y no a la inversa. EE2 no es más fuerte que EE1, lo mismo ocurre entre R1 y R2.

Hay otra visión más fuerte de P, es P3: los enunciados doctrinales no sólo tienen pretensiones de verdad acerca de estados de hechos externos, sino que pueden ser objetos de estados cognitivos, es decir, su valor de verdad puede ser conocido.

Parece que en la discusión sobre Lindbeck realmente se trabaja como un modelo mezclado: P3, EE1 y R2. Otras veces es P1, EE2, R1. Lindbeck es especialmente confuso respecto a qué se entiende por $\mathrm{R}$.

152. Adoptamos la distinción clásica entre lenguaje y sucesivos metalenguajes. Aplicado a las lenguas naturales tendríamos: lenguaje de primer orden (español), lenguaje de segundo orden o primer metalenguaje (una gramática estructural del español, una gramática generativo-transformacional), lenguaje de tercer orden o segundo metalenguaje (teoría de las gramáticas del español). En cada uno de los niveles se habla acerca del nivel anterior. Es una distinción similar a la de ciencia y filosofía de la ciencia. El origen de la terminología lenguajemetalenguaje proviene de la lógica. 
similares a las reglas de la gramática y así lo refleja el ejemplo cristológico citado por él que claramente opta por esta línea. Pero en otros casos parece dar a entender que las doctrinas son los dogmas y creencias, en sentido amplio, que mantiene una religión 153, o sea, el discurso de primer orden.

$\mathrm{Si}$ las reglas son de segundo nivel, entonces suponen siempre un lenguaje objeto sobre el que actúan. ¿Qué teoría aplicamos al lenguaje objeto, proposicionalista, expresiva-experiencial, regulativa o ninguna de las tres? Sea cual sea la interpretación 154, las creencias -tal y como los entienden los creyentes en su sentido ordinario- pretenden afirmar algo acerca de una realidad. En esto choca Lindbeck con la competencia de los creyentes 155 . Se las puede considerar reglas, pero en cuanto reglas lo que hacen es gobernar acciones. Bien sean sólo acciones mentales las que rijan: "cuando piensas acerca de Jesús lo debes hacer así”, bien sean reglas que dirijan la actividad humana 156. En el primer caso, el de las creencias teoréticas (dogmas), sigue permaneciendo un contenido proposicional, “debes pensar así acerca de Jesús porque Jesús es así”. En el segundo, creencias prácticas, no se da tal contenido proposicional.

Más confuso es, todavía, si introducimos la narración bíblica tal y como la entiende Lindbeck. ¿Es simple texto sin ninguna referencia? O sea, ¿ficción literaria? Volvemos a ir contra la competencia creyente 157. Podría pensarse que dicho texto constituye el lenguaje natural -lenguaje objeto- y las doctrinas como metalenguaje de interpretación del texto. Esta interpretación no encaja con el ejemplo cristológico del autor en el que el lenguaje de primer orden incluye las afirmaciones dogmáticas conciliares. Además, si pensamos así, difícilmente puede decirse que el texto tenga prioridad y absorba al mundo. Las reglas nos dirían cómo leer el texto.

Desde luego lo más sencillo es entender por doctrinas los contenidos proposicionales que podemos formular a partir del texto, en principio, en una interpretación del mismo. De hecho siempre se ha entendido así en la visión proposicionalista. Esto, lo más sencillo, es precisamente lo que Lindbeck no

153. "Church doctrines are communally authoritative teachings regarding beliefs and practices that are considered essential to the identity or welfare of the group in question" ( $N D$ 74).

154. Sobre este carácter algo confuso véase (Kelsey 1990, 172-173). También (Zorn 1995) que discute el papel de Wittgenstein en la teoría de Lindbeck.

155. La pretensión de verdad referencial en el lenguaje usado por los creyentes parece algo irrenunciable, véase (Lash 1990, 132-133).

156. Véase (Root 1990).

157. Véanse los acertados comentarios sobre el carácter proposicional de la religión que se encuentran en (Power 1987). 
acepta. Implica hacer intervenir la racionalidad del sujeto frente a un objeto que está delante de él -la Escritura-, objeto al que Lindbeck considera absoluto. ¿Pierde el texto bíblico importancia o dignidad frente al hombre? Si creemos que la racionalidad del sujeto expresa la realidad del mismo como imagen de Dios, entonces no cabe tal consideración. La primera revelación de Dios no es la conocida por la Escritura, sino la que se manifiesta en el ser humano por el mismo hecho de serlo, imagen de Dios y, por lo tanto, en cierta medida, autorrevelación de Él mismo.

Lindbeck parte del supuesto de que es más fácil el ecumenismo si pensamos en las doctrinas como gramática, como metalenguaje. Las reglas pueden ser las mismas y además aceptadas por todos -otra vez con el ejemplo cristológico a vueltas- aunque las formulaciones dogmáticas concretas -el lenguaje natural o lenguaje objeto- sea diferente. Esta afirmación no está clara si seguimos el ejemplo lingüístico. Las gramáticas se pueden hacer desde diferentes perspectivas. No es lo mismo una gramática estructuralista del español que una generativo-transformacional. ¿Nos pondríamos de acuerdo en las reglas? No necesariamente.

Además -aplicando ahora de forma diferente la metáfora lingüística-, supongamos dos lenguajes naturales -español e inglés- y una presunta gramática universal chomskiana. ¿Qué importa que los módulos de la gramática sean los mismos si de cualquier forma un inglés no se entiende con un español? La comunicación sigue siendo imposible. Estaríamos haciendo -contra Lindbeck-- teoría general de la religión, pero nunca ecumenismo.

\subsubsection{Verdad e inconmensurabilidad}

¿Qué ocurre con la noción de verdad? Lindbeck es poco claro y en ocasiones parece mezclar adecuación categorial y verdad intrasistemática 158.

En primer lugar respecto a la adecuación categorial: si la realidad viene determinada por el lenguaje como señala Lindbeck, entonces siempre existirá adecuación categorial en una religión, pues habrá tanta realidad cuanto la permita el lenguaje. Nunca nos quedaremos cortos en vocabulario y todas las religiones serán categorialmente verdaderas. Estaríamos ante una noción superflua. Lo que ocurre es que Lindbeck utiliza este concepto para recalcar la inconmensurabilidad de las religiones y, en el fondo, la consideración de cada una de ellas como realidades autónomas incomparables entre sí.

158. Véase (Marshall 1990, 98 n. 5) y sobre todo el artículo de (Richards 1997, 36-39), nuestra interpretación no es exactamente igual a la suya. 
En cuanto a la verdad intrasistemática: se trata de la concepción de la verdad entendida como coherencia entre los diferentes enunciados. Pero se añade la novedad de la correlación con un género de vida. Forma de vida y lenguaje se imbrican entre sí según los postulados de Wittgenstein. No sólo es la coherencia entre los enunciados como tales enunciados, sino la coherencia entre enunciado y género de vida.

La propuesta de Lindbeck implica la idea de que la verdad no es una propiedad de la relación entre el lenguaje y mundo al que se refiere el lenguaje, sino de la relación entre forma de vida que se adopta y mundo en el cual uno ha sido absorbido. Mundo, éste último, creado por el lenguaje, por el texto, y que constituye la auténtica referencia creyente. Los enunciados proferidos serán verdaderos sólo si están en conformidad con dicha forma de vida adoptada al ser absorbido el sujeto por el texto. En sentido propio sólo de las formas de vida consideradas como un todo puede decirse que son verdaderas o falsas, pues sólo ellas son las que establecen relación a la realidad textual.

En principio parece una concepción de la verdad de los enunciados religiosos cercana a la de Barth ${ }^{159}$. En realidad Lindbeck simplifica demasiado la cuestión, pues los problemas que plantea el lenguaje religioso son numerosos. Podríamos distinguir con Hunsinger 160 cuatro dominios a la hora de aquilatar términos en relación a las afirmaciones de Lindbeck:

a) El dominio del lenguaje. Si consideramos sólo los enunciados en su formulación linguiística tendríamos que existe una pretensión de inteligibilidad al formularlos y que hay que resolver los problemas de consistencia interna, sentido o significación y lógica de dichos enunciados.

b) El dominio de la relación entre lenguaje y realidad "divina", realidad que es exterior al lenguaje. Hay una pretensión de verdad en el lenguaje. Aquí se plantean los temas del contenido cognitivo de los enunciados. Habría que elaborar una teoría de la referencia y otra de la predicación en los enunciados de fe.

c) El dominio de la relación entre lenguaje y realidad social. Los enunciados pretenden ser correctos. Aquí estarían los asuntos de la performatividad del lenguaje y la relación entre lenguaje, normas de comportamiento y valores.

159. Lo expone Hunsinger señalando que es un axioma de la teología de Barth el que la verdad del evangelio cristiano tiene un carácter implicativo, es self-involving, véase (Hunsinger 1993, 41).

160. Véase (Hunsinger 1993). También (Alston 1995). 
d) El dominio de la relación entre lenguaje y realidad mental. Aquí está implicada la pretensión de veracidad del lenguaje. Corresponden los temas de la intención, sinceridad y expresividad del lenguaje religioso.

Para Lindbeck la corrección (rightness) es condición necesaria de la posibilidad de verdad (truth), pues lo que corresponde a la realidad última es como un todo la forma de vida creyente. Es una especie de coherentismo social donde la forma de vida es el vehículo semántico a través del cuál deben pasar las textos de la Escritura en orden a exponer la realidad divina 161. Esta concepción está muy lejana de lo que los creyentes entienden por verdad de sus afirmaciones. Si un cruzado dice "Jesús es Señor", antes de cortarle la cabeza al infiel de turno, podremos decir que en tal contexto social el uso de la expresión es incorrecto, pero ello no implica la falsedad de la expresión en cuanto enunciado.

Si nos fijamos en el segundo concepto de verdad que desarrolla Lindbeck y decimos que el carácter proposicional está en función de su proclamación, entonces afirmamos la performatividad de los enunciados como condición para poder hablar de verdad 162. Una cosa es la proclamación de un enunciado y su asunción como verdadero y otra la verdad objetiva del mismo. ¿Crea la afirmación de verdad, la verdad proposicional del enunciado? La verdad o falsedad son propiedades de la relación entre lenguaje y mundo, no de la relación entre hablante y enunciado. Una vez que asumo un uso declarativo del lenguaje -lo cual supone que tengo algo que describir y por ello no me vale el ejemplo que pone Lindbeck acerca de "este coche es rojo" sin coche delante porque ahí no hay ningún uso declarativo-, entonces, admitida la situación declarativa, el tema de la verdad afecta a la conexión entre lenguaje y mundo. Un asunto diferente es que yo pueda comprobar o no si mi enunciado es verdadero o falso y que la proclamación del mismo manifieste un compromiso, una apuesta, por lo dicho que sea más o menos razonable. En todo caso la verdad o falsedad no la creo yo al proferir el enunciado. En esto Lindbeck en cierto modo lo que hace es marginar a Dios y al "mundo divino". Es un un círculo vicioso donde sólo hay hablante, realidad creada por el lenguaje y afirmación de que lo creado resulta verdadero. No hay trascendencia. ¿Dónde queda Dios? 163.

161. Véase (Hunsinger 1993). Según Hunsinger se trataría de un modelo mucho más cercano al esquema tomista de naturaleza-gracia, que al modelo de Barth.

162. "It is only through the performatory use of religious utterances that they acquire propositional force" (ND 66).

163. El tema de la performatividad se lo discute a Lindbeck muy bien (Richards 1997, 48ss). Los credos son enunciados de actitudes proposicionales. 
Después de todo, al final resulta que la verdad de los enunciados depende de su uso para conformar nuestras vidas, Lindbeck parece caer en un concepto pragmático de verdad 164.

Pasemos al tema de la inconmensurabilidad entre los diferentes credos religiosos. Al ser la verdad un asunto interno a la relación entre forma de vida y doctrina religiosa no podemos elaborar una teoría general de la verdad válida para juzgar todas las religiones. Desembocamos en una sucesión de diferentes paradigmas, cada uno de los cuales es autosubsistente y verdadero. $\mathrm{La}$ asunción aquí de la filosofía de la ciencia de Kuhn desemboca en un fideísmo relativista 165 . No hay una posición neutral desde la cual se puedan comparar los diferentes sistemas de creencias.

Según Tilley, el fideísmo vendría propiamente de combinar inconmensurabilidad con intratextualidad. Si los significados son internos al texto no hay salida posible del fideísmo. Lindbeck no se fija en que las diferentes comunidades religiosas están inmersas en distintos contextos culturales. Es toda una cultura la que atraviesa a la propia comunidad religiosa 166. Hay siempre, como hemos visto, un contexto de interpretación más allá del puro texto considerado en abstracto. De ahí que abogue Tilley por un intratextualidad moderada (dirty) y no radical.

Lindbeck insiste en el ejemplo del amor budista, amor cristiano y fraternidad ilustrada como tres realidades diferentes, difícilmente traducibles entre sí. En realidad tenemos el mismo problema en el interior de la comunidad cristiana 167. Existe en todos los casos un contexto de interpretación que media el texto bíblico. Los postliberales no clarifican la relación entre significado intratextual y contexto de interpretación que implica factores extratextuales. En realidád rechazan cualquier contexto de interpretación.

164. Véase (Hunsinger 1987, 222, n.20). Mientras no exista una teoría fuerte para la verdad como correspondencia en el lenguaje religioso, la alianza de Lindbeck con el pragmatismo ofrece un aceptable modo de justificación, así piensa (Reynolds 1997, 45). Curiosamente McFague, a pesar de su radical diferencia con la línea postliberal, coincidiría en lo mismo en opinión de (Reynolds 1997, 45). También insiste en el pragmatismo (Emmanuel 1989) que muestra cierta similitudes entre Lindbeck y Kierkegaard.

165. Véase (Tilley 1989) que recoge las críticas. Siguiendo a Kuhn las teorías, métodos y valores son incomunicables y sometidos a una carga de relativismo, véase sobre Kuhn y Lindbeck la excelente exposición de (Rigby, Hengel and O'Grady 1991, 671-676). Recuerdan que la relación es con el primer Kuhn y plantean que pasaría si se utilizase otra teoría de la ciencia, la de Laudan por ejemplo.

166. Bien observado por (Tilley 1989, 96-97). El error de Lindbeck sería separar la explicación del texto como acción comunicativa, de la audiencia sobre la cual la acción se realiza (Ibid 99). Ver también (Albrecht 1995).

167. ¿Es el mismo concepto de amor cristiano el que tiene una comunidad de base fiel a la teología de la liberación que el de un grupo carismático? 
Vista la concepción que tiene Lindbeck sobre la verdad de los enunciados y la inconmensurabilidad entre las diferentes religiones, resulta que el único criterio que tenemos para hablar de la verdad de una religión es su capacidad de captación. En definitiva, su éxito 168 . ¿Se desemboca con las propuestas de Lindbeck en el aislacionismo, imperialismo y fideísmo? 169, más tarde lo volveremos a discutir. De todas formas la capacidad de convicción de una religión y su éxito, parece ser la única forma que tenemos, según Lindbeck, de decidir sobre la verdad de las religiones.

Concluyendo, Lindbeck identifica teoría del significado y teoría de la referencia en el lenguaje religioso. La referencia viene creada por el significado. No existe una realidad extralingüística o al menos permanece totalmente desconocida. Lo único que tenemos es la realidad creada por el lenguaje.

\subsubsection{Temas particulares}

Hay muchos más temas que se le han discutido a Lindbeck. Por ejemplo, le ha sido muy criticada la interpretación que hace de Schleiermacher como adalid de una postura expresiva-experiencial. No estaría tan acertada dicha lectura a los ojos de algunos especialistas 170.

También la afirmación concreta que hace de las tres reglas cristológicas le ha sido contestada 171.

En unas páginas del libro se ocupa Lindbeck del tema de la salvación de los no cristianos. Aprovecha para criticar las afirmaciones de Rahner sobre los cristianos anónimos y presenta una teoría que, cuando menos, se la puede tildar de estrafalaria 172.

Los asuntos ecuménicos le han sido asimismo discutidos 173. Igualmente se ha comentado la exposición que hace del consensus ecclesiae como base respecto al establecimiento de doctrinas 174 .

168. "Success will tend to justify the Christian community in taking coherence with that network of belief and practice as the primary (...) criterion of truth, and failure will suggest that it is not justified in doing so" (Marshall 1990, 82-83).

169. Véase (Marshall 1990, 82-90).

170. Véase (Behrens 1994) y (Gerrish 1988) que critican tal encasillamiento.

171. Véase (Williams 1988) y (Bryant 1993).

172. (ND 55-63). Los comentarios de (DiNoia 1990) y (Stell 1993). Para el tema de la diversidad de religiones ver también (Surin 1988) y (D'Costa 1994).

173. Véase (Root 1990), (Frei 1990a), (Wainwright 1988) y (Phillips 1988).

174. Así (Rigby, Hengel and O'Grady 1991) destacan los graves e insuperables problemas prácticos que tiene la propuesta de Lindbeck. Sólo se puede identificar una comunidad teóricamente, en la práctica no se puede dar, hasta ahora, un ejemplo de cómo llegar al consenso. 


\subsubsection{La religión como lenguaje o cultura}

La asimilación de religión a lenguaje o cultura no es tan obvia. Lindbeck utiliza un modelo antropológico que vale para sociedades cerradas, pequeñas y profundamente integradas. Un grupo étnico de la Amazonía, una cultura polinésica o una tribu de Indonesia quizá respondan al modelo que adopta Lindbeck. Nuestra sociedad occidental contemporánea no. Con el lenguaje y la cultura occidental prácticamente se nace. Mejor dicho, se adquiere desde la primera infancia un lenguaje, el que sea, y una cultura. ¿Sucede así con el cristianismo? En la edad media quizá fuera igual de natural aprender la lengua materna y el cristianismo. El mundo era cristiano. Hoy no, la religión se adquiere. $\mathrm{O}$ mejor, implica una decisión consciente, una opción por ella. Uno no opta por hablar castellano si nace en una familia de Valladolid; del mismo modo se nace dentro de una cultura secularizada, científica y racional. No hay opción posible por ella. En nuestro caso se está dentro de ella. Precisamente por eso el abrazar una religión implica una opción personal. De forma más o menos conflictiva se planteará una decisión personal por vivir como cristiano o no. Y toda opción de este tipo es en alguna medida racional. Supone un juicio racional de aquello que se te invita a creer. De ahí que la comparación entre religión, lenguaje y cultura plantee dificultades.

Además, en algunos casos no existe -en nuestra sociedad- ni siquiera la posibilidad de hacer esa opción por mantener una fe de la infancia, pues ésta nunca ha existido. Entonces la oferta religiosa es completamente extrínseca al sujeto. Mayor motivo aun para que se juzque desde la razón. Juicio de la razón que no es necesariamente del modo como se examina una prueba de laboratorio o una deducción matemática. Posiblemente la mayoría de las veces sólo sea un juicio implícito en virtud de la racionalidad latente de la que se participa. En esta racionalidad científico-técnica, democrática y secularizada, estamos como en nuestro medio natural, es nuestra cultura. Por ello lo que se oferta para creer es valorado y elegido por los sujetos, de forma más o menos consciente, en virtud de ese sentido común, de esa racionalidad común.

Lindbeck da a entender con su identificación entre religión, lenguaje y cultura que en nuestro caso puede ocurrir como con la religión de cualquier grupo étnico africano o amazónico. Se acepta todo un cuerpo de creencias en las cuáles nace, vive y muere el sujeto. Entre nosotros no es así, el sujeto nace, vive y muere dentro de una cultura con una racionalidad determinada por la historia del pensamiento occidental, cargada de filosofía, ciencia y tecnología. Y cultura, no hay que olvidarlo, con pretensión de universalidad 175. Es en ese medio donde se oferta la religión y donde se decide.

175. Como bien recuerdan Apel y Habermas. 
En ocasiones existe el prejuicio de valorar negativamente esta situación del hombre occidental. Es un prejuicio, bastante católico -no sé si protestante-, que supone una desconfianza en el ser humano como hijo de Dios, creado a imagen suya. Cuando el hombre actúa limpia y honradamente siguiendo su razón -razón intersubjetiva que es compartida por el lenguaje-, y trata de crear una situación ideal de comunicación en la búsqueda de lo mejor entonces, en términos teológicos, podríamos decir que es cuando más se acerca el ser humano a la manifestación de su condición de imagen de la comunidad trinitaria. Si la capacidad de pensamiento, comunicación y creación es lo más divino del ser humano, parece que la actuación racional es lo que más le acerca a Dios 176 . Su racionalidad no puede ser más que espejo de la racionalidad perfecta que es Dios. Lindbeck niega la existencia de estándares universales de racionalidad y argumenta que las formas humanas de razonamiento están enraizadas y conformadas por las formas de vida de las cuales surgen 177; el cristianismo hay que explicarlo desde sí mismo, no hay una racionalidad universal compartida. Sin embargo, la asunción de principios universales permite una distancia crítica respecto a las creencias religiosas en su permanente tendencia a convertirse en ideología. Pensar lo contrario nos llevaría a considerar las religiones como absolutos intocables en sí mismos. Desde la posición de Lindbeck da la impresión de que no se puede criticar la propia religión, el modelo que presenta es de integración plena en la misma. Pero es perfectamente lógico decirle a una religión si afirma posturas de racismo, de inferioridad de la mujer, de violencia, o de comportamientos míticos respecto a la sangre o al sexo, que tales afirmaciones son, literalmente, falsas. Se impone, pues, una distancia crítica respecto a la ideologización que toda religión, normalmente por influencias -esta vez sí- culturales, tiende a hacer y que Lindbeck no parece considerar. Además este modo de actuación es el único que hay para salvaguardar la dignidad de la religión, el núcleo de creencias profundas que la constituyen. Ninguna religión, como ningún lenguaje o cultura, es absoluta en sí.

176. Y no tanto su capacidad pasional, como algunos modelos de Dios sugieren hoy en día. De todas formas habría que discutir más en profundidad el tema. El libro de Sallie McFague es espléndido.

177. En $N D$ se produce un fraccionamiento continuo de la razón. Es una razón débil. El tema del texto y de la narratividad fracciona la razón y la comunidad respecto a la sociedad. Existe una fractura además en las relación entre experiencia y tradición que se convierten en alternativas excluyentes. Habría que volver a Kant en búsqueda de la unidad de la razón y la unidad de la experiencia, véase (Godlove 1987). En el fondo cae Lindbeck en la razón débil postmoderna. 
Insiste Lindbeck en que el pensamiento y la experiencia están conformados por la tradición y la cultura, no hay fundamentaciones trascendentales. Ahora bien, los cambios históricos de hecho se dan, se influye en las tradiciones y las culturas cambian. Al buscar un fondo irreformable para anclar la identidad cristiana, lo que logra es que dicho núcleo no resulte afectado por la historia ${ }^{178}$ y con ello pierda, paradójicamente, la historicidad de la situación humana.

Podrá decirse que el embarcarse en una religión no implica a la razón, que no es necesario. El problema entonces es cómo diferenciar religión de secta. ¿Acaso todo vale? La razón juzga la credibilidad de enunciados, pues si de lo que se trata es de aprender unas reglas de juego, o practicarlas, sin una valoración previa, entonces lo que se hace es entrar en el marketing, en el mercado de creencias, hasta el fondo. El cristianismo debe presentar la verosimilitud de un cuerpo de creencias y de normas de comportamiento. Unas religiones son, de hecho, más verosímiles que otras. Lindbeck parece suponer tácitamene que igual de válida es la confesión católica que la mormona, o la budista que la cristiana. Pero lo que hay que hacer es ponerse en el mismo medio: la sociedad occidental secularizada y ahí ver qué es más verosímil: no es lo mismo ser cristiano, mormón, testigo de Jehová o miembro de la última secta de creyentes en cometas. Si apelamos sólo a lo integrativo y no a lo racional caemos en el peligro del todo vale. Es dudoso que se aprenda a ser religioso por integración y que las doctrinas estén en segundo plano, o al menos es dudoso que deba ser así 179 .

Además, en otro orden de cosas, lenguaje y la cultura categorizan la realidad de forma previa pero sólo hasta un límite. Hay una necesidades humanas universales a las cuáles cada cultura trata de dar respuesta. Hay una nece-

178. Véase (Bryant 1993, 35).

179. Desde una racionalidad universal compartida previa a la asunción concreta de creencias (la racionalidad neomoderna de Apel y Habermas) y que, repito, teológicamente se interpreta como fruto de la creación y de la imagen de Dios en el hombre e, históricamente, puede considerarse fruto del éxito del cristianismo (tesis de Gauchet), es posible criticar todas las razones religiosas. Un sistema religioso de creencias debe ser coherente, si hay contradicciones internas puede ser descartado por su falsedad racional. Es el caso que ocurre con el politeísmo, contradictorio con el concepto de Dios. Además no debe existir contradicción entre el sistema de creencias religiosas y el resto de conocimientos racionales poseídos. Es tarea de la Teología filosófica el realizar esta labor de desbroce. En tercer lugar, vistos sistemas de creencias coherentes en sí mismo y no contradictorios con el resto de conocimientos racionales, hay que buscar en qué sistema hay mayor verosimilitud. La Epistemología religiosa tiene aquí su papel. Teología filosófica y Epistemología religiosa son los dos focos de la actual Filosofía de la religión. 
sidad de comunicación que los lenguajes resuelven. Y en ciencia, por más que se diga, siempre está la realidad empírica detrás. Y no hay que olvidar que las teorías científicas desembocan en tecnología y esta en manipulación de la realidad y bienestar. La experiencia está detrás. ¿Por qué se acepta una religión si no hay necesidad o demanda previa? Otra cosa es que las diferentes respuestas tengan una base común o no. Es un problema parecido a la discusión sobre los universales linguísticos. Lo que sí hay es la necesidad de comunicación común. Esto Lindbeck no lo considera.

La metáfora linguiística sirve y no sirve a la vez. El cristianismo es como un lenguaje natural, el español. Hay otras religiones. Son lenguajes diferentes como el inglés o el alemán, ni más verdaderos ni más falsos. Cada lenguaje sitúa de un modo peculiar a los hablantes en el mundo. Hacen ver el mundo de forma diferente. Esto sería discutible, de todos modos vamos a aceptar que Sapir y Whorff tienen razón. Los hablantes nativos de un lenguaje tienen competencia lingüística, saben hablar el lenguaje, conocen el vocabulario y la sintaxis y, tácitamente, conocen cuándo una oración está bien formada en su lengua y cuándo no. Los hablantes nacen en una comunidad lingüística concreta y aprenden su lenguaje materno sin darse cuenta. Hasta aquí muy bien, pero ¿por qué hay lenguajes naturales, por qué existe el español y el inglés? Porque todos los seres humanos tienen una necesidad común, la de comunicarse. Esto no lo dice Lindbeck, si lo quisiera decir tendría que recuperar algunas propuestas de las teorías expresivo-experienciales. Si hablamos de culturas es lo mismo. Hay unas necesidades humanas a las cuales las culturas tratan de dar respuesta. Las culturas son diferentes, las necesidades: alimentación, organización social etc. son las mismas. Si nos planteamos como Chomsky la búsqueda de una gramática universal subyacente en las estructuras cognitivas humanas, y le damos una respuesta positiva como él hace entonces sí que la metáfora de Lindbeck se derrumba 180. Además ¿para qué se usa un lenguaje? Hay diferentes funciones: expresar sentimientos, dar órdenes, describir la realidad... 181. Una de ellas es describir la realidad externa al lenguaje. En español hablamos de estrellas y de lagartijas. Objetos reales. También contamos historias, pero el contar historias no es lo único que hace el lenguaje. La función descriptiva del lenguaje la deja Lindbeck en el

180. Incluso se puede hablar de universales lingüísticos léxicos. Es una visión muy peculiar del lenguaje la que toma en cuenta Lindbeck.

181. Como ya Jakobson estableció. 
aire. Es una intuición básica de los creyentes, que cuando están hablando de que Jesucristo resucitó están diciendo algo sobre una realidad que trasciende al propio lenguaje. Responder a esta intuición básica de los hablantes nativos de la lengua supondría aceptar parte de la teoría proposicionalista.

Hoy hablamos español y en el siglo XV también se hablaba. Ahora se habla en Castilla y en las orillas del Amazonas. ¿Es el mismo lenguaje? Digamos que es español y hay una continuidad entre el del siglo XV y el actual, entre el de un ribereño amazónico y el de un vallisoletano. Pero difícilmente se entendería un taxista de Madrid con un pastor de la mesta. Y también es complicado que el campesino andino se entienda con un punky sevillano. De cualquier forma todos hablan español. Hay unas reglas y unas constantes latentes que permiten afirmar que lo que ellos hablan es español y no inglés. Aquí la intuición de las doctrinas como reglas sí que la creo aprovechable, sirven para explicar una identidad que permanece a pesar de los cambios históricos 182. Como la veo práctica para resolver otros casos. Un lenguaje está evolucionando todos los días pues las necesidades de comunicación van cambiando. Los hablantes nativos lo resuelven sobre la marcha, en la práctica. Un ejemplo claro es el de la informática, cientos de palabras y de giros que se introducen en el habla diaria para que los hablantes puedan entenderse. ¿Qué dicen los académicos de la lengua? Sopesan una y otra vez si un término o una expresión son correctos. Quizá tras años de deliberación introducen en el diccionario un nuevo vocablo o permiten un nuevo giro en la gramática. La competencia de los hablantes nativos ya había resuelto años atrás el problema pues había buscado como entenderse en esa nueva situación. El español es lo que los hispanohablantes hablan, no lo que los académicos determinan. O mejor, los académicos deciden a partir de lo que los hispanohablantes dicen. Si un giro entra en el habla diaria, eso es inamovible.

¿Se adquiere el lenguaje por inmersión lingüística? Lindbeck supone que sí. Creo que no vale. Valdría si fuera la primera lengua. Un niño aprende así, el problema es en el caso de una segunda lengua adquirida de adulto. Todo el que haya aprendido de mayor un segundo idioma sabe que hay que estudiar la gramática y el vocabulario, que no es lo mismo dejar a un español de dos años que a uno de cuarenta en medio de Alemania. Hoy la religión es un segundo lenguaje adquirido de adulto. El lenguaje religioso no se adquiere por inmersión lingüística.

182. En este sentido insiste (Kelsey 1990) con acierto en mi opinión. 


\section{Consideraciones finales}

Antes de terminar hagamos unas breves consideraciones de conjunto.

\subsection{Dependencia de la teología respecto a la filosofía}

La primera nota que trae $N D$ es una referencia a la Estructura de las revoluciones científicas, ello ya da una idea de por dónde pueden ir los tiros. Una religión es como un paradigma científico que nos hace ver la realidad en una forma determinada y exclusiva. Los paradigmas son inconmensurables entre sí, no hay traducción posible. La influencia de Wittgenstein también es evidente a lo largo de toda la obra 183 . Lindbeck de modo expreso se remite a sociólogos y antropólogos como Winch, Geertz, Berger, Smart y Christian. La referencia última siempre es Kant y su teoría del conocimiento: los noúmenos son inalcanzables, mantengámonos en el nivel de los fenómenos.

A Lindbeck se le puede aplicar el viejo refrán castellano de "dime con quién andas y te diré quién eres". Porque al ir de la mano de Wittgenstein, Geertz, Chomsky ${ }^{184}$ y Kuhn así sale lo que sale 185.

Ahora bien, qué pasaría si Lindbeck se asociara con Marvin Harris en lugar de hacerlo con Geertz. Las culturas ya no serían realidades tan estancas pues, a fin de cuentas, una cultura no hace más que dar respuesta a una misma serie de necesidades humanas, biológicas y psicológicas que están detrás. ¿Y si en lugar de fijarse en la competencia chomskiana lo hiciera en los universales lingüísticos o en la gramática universal? ${ }^{186}$. Porque Chomsky ha insistido una y otra vez en una serie de componentes gramáticales fruto de la estructura mental humana común a todos. Chomsky desemboca en una psicología cognitiva de la especie humana. Del mismo modo todo lenguaje no es más que una res-

183. Exclusivamente el segundo Wittgenstein de las Investigaciones filosóficas. Curiosamente no cita a Phillips y las aplicaciones que hace a la religión de la obra de Wittgenstein. Es lo que se ha dado en llamar fideísmo wittgensteiniano que, en mi opinión, encaja con las tesis de nuestro autor.

184. De Chomsky la referencia está siempre en su teoría de la competencia lingüística.

185. Incluso podríamos añadir algún otro que se echa en falta. No está Quine ni su gavagai. Tampoco Feyerabend. Placher sí utiliza a Quine y en (Lindbeck 1994a) se amplía el abanico de citas, aparece MacIntyre.

186. A propósito de los universales lingüísticos: el caso de los colores al que nos hemos referido es ambiguo en relación a la tesis de Lindbeck. Las lenguas categorizan la realidad (el color) de diferentes formas, hay lenguas que sólo distingen entre blanco y negro, otras -como la nuestra- utilizan todo un arco iris de términos. Ahora bien, el trabajo de Berlin y Kay desmentiría posturas relativistas, pues estaríamos ante un caso de universales lingüísticos considerados como condicionales. Habría once categorías básicas para clasificar los colores, de las 
puesta a una necesidad humana básica que está detrás. La necesidad de comunicación. No digamos nada si en lugar de aliarse con Kuhn 187 lo hace con Popper o con Lakatos. O con Ricoeur, Jauss o Iser en lugar de hacerlo con Auerbach.

Teológicamente se ha comentado que las raíces están en Barth 188. Es un tema discutible. En parte sí y en parte no, pues si -por ejemplo- el valor cognitivo de una aserción teológica depende de la corrección de la actuación de la comunidad en una forma de vida correlativa al texto, entonces estaríamos degradando la realidad divina 189.

En cualquier caso, es evidente que determinados compañeros de viaje inciden en la perspectiva de Lindbeck de una forma decisiva. Ahora bien, ¿por qué elegir éstos? No tienen por qué ser ellos, puede haber otros con resultados muy diferentes. Hay muchas posibilidades a la hora de hacer un cocktail 190.

cuales cada lengua tomaría un subconjunto. Se utilizan desde dos hasta once y entre ellas se dan ciertas relaciones de condicionamiento:

$$
\begin{aligned}
& \text { blanco }<\text { rojo }<\underset{\text { verde }}{\text { amarillo }}<\text { azul }<\text { marrón } \\
& \text { negro } \\
& \begin{array}{l}
\text { morado } \\
\text { naranja } \\
\text { gris }
\end{array}
\end{aligned}
$$

De esta forma, si una lengua tiene término para el color azul, necesariamente tiene términos para los colores que se encuentran a la izquierda de éste. Además se ha sugerido que este esquema corresponde a los estadios por los que atraviesa, en su desarrollo, la lengua de un pueblo en lo que respecta a los términos para colores. Habría una sucesión fija de etapas históricas por las que una lengua debe pasar a medida que su vocabulario aumenta. Con ello - la hipótesis se convierte en un universal sobre la evolución del lenguaje. No se prejuzga la posibilidad o imposibilidad de traducir con exactitud los términos unos por otros pues habría siempre unos casos centrales en los que existiría el acuerdo (lo que llaman los autores "focos"). Si una lengua tiene un nombre de color con foco $\mathrm{x}$, entonces también tiene un nombre de color para cada foco a la izquierda de $\mathrm{x}$ en el diagrama. Al hablar de los focos se usan los términos en forma coincidente. Esas coincidencias centrales son las que permiten comparar términos de diferentes lenguajes. Así pues, las lenguas categorizan la realidad, pero podemos ver una estructura que determina tal categorización. Véase (Leech 1974, c. 11), (Hierro S. Pescador 1980, 69-81) y (Comrie 1989).

187. De todas formas la alianza es con el primer Kuhn como es obvio por la fecha del libro. Kuhn al final de sus días mantuvo una noción de inconmensurabilidad muy diferente.

188. "Lindbeck substantive position is a methodologically sophisticated version of Barthian confessionalism. The hands may be the hands or Wittgenstein and Geertz but the voice is the voice of Karl Barth" (Tracy 1985, 465). El texto es recordado por (Hunsinger 1993, 92).

189. La afirmación del cruzado, citada por Lindbeck, para Barth sería un sinsentido, no un enunciado falso. Para la crítica a Tracy sobre el uso de Barth en Lindbeck véase (Hunsinger 1993).

190. El tema nos lleva de paso a una reflexión sobre la relación filosofía-teología. Toda teología está en función de una filosofía previa que se escoge. Al hacer teología hablamos 


\subsection{Sentido general del libro}

¿A quién va dirigido el libro, cuál es su audiencia? Lindbeck indica al comienzo de la obra que ante todo le mueve una preocupación ecuménica. El haber estado años y años en diálogos intereclesiales con tan pocos resultados prácticos es un hecho latente a lo largo de las páginas. Solución radical: si no nos ponemos de acuerdo con los dogmas y la presunta realidad que describen, entonces lo mejor es llegar a la conclusión de que un dogma no describe ninguna realidad. Sólo funciona como regla de un lenguaje. Lindbeck parece estar harto de discusiones sobre creencias.

Este trasfondo ecuménico es el principio rector que guía la lectura del libro 191. Ahora bien, lo lógico sería entonces que pusiera toda la carga en ir contra la visión proposicionalista de las doctrinas 192. Sin embargo no lo hace así y, aunque parezca extraño, el enemigo número uno de sus páginas es la visión expresivo-experiencial. ¿Por qué? La respuesta está al final. Cuando se llega a las últimas páginas se descubre el porqué de la amargura que en ocasiones destila la obra.

En el último capítulo reconoce el autor que hay una profunda insatisfacción personal ante la actividad pastoral de las iglesias. Ya no estamos, pues, ante un problema interreligioso, sino intrarreligioso. Se trata de un fenómeno generalizado. Años de aggiornamento, de cambios, de innovaciones y... la gente se continúa desapuntando del cristianismo. El cristianismo pierde relevancia. Estamos en época postmoderna y de religión light, cada uno cree lo que quiere o le conviene y la secularización entre los creyentes es rampante. ¿Por qué? Lindbeck le echa la culpa, más o menos inconscientemente, a la visión expresivo-experiencial de la religión que ha inspirado la práctica pastoral de las iglesias. No se trata sólo de un fracaso ecuménico, sino del fracaso pastoral generalizado del cristianismo en las sociedades occidentales del primer mundo 193. De ahí que a lo largo de todo el libro el enemigo a batir sea la corriente expresivo-experiencial y su versión mixta de proposicionalismo.

sobre Dios, pero hablamos nosotros con nuestro lenguaje y nuestra razón. Es imprescindible una filosofía, sègún cuál se escoga así será la teología. Dado que hoy hay mucho más para escoger que en cualquier otro momento de la historia, hoy -más que nunca- la teología es ancilla philosophiae.

191. Hasta tal punto que Frei indicó que "without the absolute priority of that Christianecumenical reality, without its reality, forget the "rule" or regulative approach, forget the cultural-linguistic theory, forget the book" (Frei 1990a).

192. Lindbeck caricaturiza mucho a los proposicionalistas, así piensa (Gerrish 1988,88 ).

193. Que, además, si en los países católicos latinos es preocupante, en las sociedades protestantes anglosajonas debe ser de escándalo. De paso hay que indicar el carácter más abier- 
La solución de Lindbeck es clara. Cambiemos de rumbo, busquemos comunidades plenamente integradas, dejemos que el texto absorba a los lectores, que las creencias sean reglas de identificación. En definitiva, hablemos un lenguaje propio que nos distinga de los otros. Un lenguaje que sólo entendamos nosotros y, el que quiera entrar, que lo aprenda. Adoptemos una especie de nacionalismo eclesial, hagamos un ejercicio de autoafirmación 194. Dejemos que el mundo corra, nosotros a lo nuestro. Integración dentro, diferenciación de los de fuera y, sobre todo, identidad -palabra mágica-. Lindbeck lo afirma descarademente: seamos una secta 195.

La tendencia que Berger y otros sociólogos de la religión llevan años notando: la progresiva sectarización de las religiones institucionalizadas dentro de las sociedades secularizadas, Lindbeck lo convierte en situación deseable. Más aún, lástima que no estén todavía más secularizadas las sociedades. Lamentablemente todavía estamos en una situación intermedia. Así pues, vamos camino de ser una secta... y a mucha honra. Una secta en lo alto de un monte a la que todos puedan ver como comunidad de contraste y alternativa ante la sociedad 196.

A lo largo de páginas anteriores ya hemos reflejado algunas de las críticas que ha sufrido Lindbeck. Después de esto último es evidente que hay que añadir las de sectario y conservador 197. Su modelo propone la automarginación de los cristianos de la discusión pública 198. Alegando que los cristianos

to de la teología americana a la base pastoral. Los editores de la edición alemana lo reconocen, véase (Lindbeck 1994a, 8-9).

194. "Even if failing to win them legitimacy in the eyes of others, their performance may succeed in winning them legitimacy in their own eyes, which means that it may succeed in setting the foundations of a new practice and community of inquiry rather than in reforming an existent one" (Ochs 1990, 234-235).

195. Véase (Kelsey 1990, 12-18). Esta afirmación ya viene de antiguo en Lindbeck. Aparece en artículos previos a $N D$. Su propuesta de sectarización es sobre todo sociológica. Ante la sociedad desacralizada los cristianos deben ser una secta. No en sentido teológico, recuerda Kelsey, pues en el interior de la secta debe reinar el ecumenismo entre las diferentes comunidades cristianas; ecumenismo que vendría favorecido adoptando su teoría de las doctrinas como reglas. Secta entendida como reducido grupo de personas cuyas creencias y comportamiento están agudamente diferenciadas de la sociedad circundante.

196. "The Church as an ecumenical, exclusivist, engaged sect" (Kelsey 1990, 18).

197. Ya en una de las primeras recensiones se afirma: "It is here that we come upon the danger of Lindbeck's interpretation of doctrine, which lies in its profound conservatism. By arguing that the justification of religious statements lies in their capacity to articulate the grammar of the faith, Lindbeck offers the perfect formula for ecclesiastical self-perpetuation" (Corner 1986, 112). También se le ha tildado de tribalismo e imperialismo teológico, véase (Placher 1994, 115).

198. Kelsey trata de salir al paso a las críticas hechas. Recuerda que lo que busca Lindbeck es ante todo la integración de la comunidad. De todas formas, afirma que sólo las sectas 
hablamos otro lenguaje, la propuesta del modelo lingüístico-cultural es la de acurrucarse ante la adversidad 199.

\subsection{Revisionistas y postliberales}

El libro de Lindbeck tuvo un inmenso eco. No hacía más que reflejar, con acierto, una insatisfacción latente. Plasmaba lo que muchos compartían sin saberlo articular 200.

Obviamente la propuesta de Lindbeck no podía quedar sin respuesta. El debate estaba servido. Numerosas voces se han alzado contra él y, de ellas, Tracy ha sido el portaestandarte 201. Ha encabezado la oposición en un debate intelectual de altura que todavía continúa. Frente a los postliberales se levantan los revisionistas 202. Esta vez Chicago le devuelve la jugada a Yale.

exclusivistas sobrevivirán en nuestra cultura. Aunque parezca extraño esto tiene un aspecto provechoso, según él, tanto para la Iglesia como para la sociedad en cuanto toda sociedad necesita inconformistas que planteen alternativas radicales. Recuerda que en ningún lugar está escrito que la Iglesia deba ser un agente del bien común público, un colchón del bienestar social, véase (Kelsey 1990, 7).

199. "Claiming to speak another language, the cultural-linguistic model simply curls up in the face of them like the unfortunate hedgehog before the advancing lorry. It is not always the best recipe for survival" (Corner 1986, 113), también (Gerrish 1988, 92).199.

200. Véase (Frei 1990a, 276). Ejemplo al canto. Años enteros de catequesis de confirmación, de métodos que parten una y otra vez de la experiencia de los jóvenes, de sus inquietudes y anhelos. Cientos de grupos, de pascuas juveniles... y al final ¿qué? Resulta que cuando de adolescentes se pasa a jóvenes, y sobre todo a adultos jóvenes, se pueden contar con los dedos de la mano los que hay en las parroquias. ¿Donde están las parejas de treinta a cuarenta años, recién casados y con profesiones liberales o técnicas? Han desaparecido como por ensalmo. Para colmo de males cada vez tiran más de los jóvenes las actividades humanistas y de voluntariado al margen de las confesiones religiosas. Las ONGs pululan por doquier. Ya no hace falta pasar por las iglesias para encontrar cosas concretas que hacer y modos de actuar por los demás desinteresadamente. Al final resulta que, en la mayoría de los casos, las únicas comunidades fuertes son o los neocatecumenales o los "nuevos movimientos". Lindbeck y Tracy, postliberales y revisionistas, no hacen más que plasmar teóricamente un debate que está candente en el día a día pastoral. ¿Por dónde tirar?

201. David Tracy (1939-), sacerdote católico, discípulo de Lonergan y profesor en la Universidad de Chicago desde 1969. Sobre Tracy véase (Sanks 1993) y (Stell 1993). También (Placher 1989, 155-159) y (Hodgson 1994).

202. La oposición entre corrientes de interpretación teológica se establece con una serie de etiquetas tales como experiential-expressive frente a cultural-linguistic (así Lindbeck); hermeneutical-political frente a grammatical-confessionalist o correlational frente a intratextual (así Tracy); foundationalist frente a antifoundationalist (así Thiemann); revisionist frente a post liberal; renewal frente a transformation, así (Hodgson 1994, 60). Véase (Stell 1993, 679), tam- 
Desde el principio Tracy se ha opuesto a los planteamientos de Lindbeck 203. Retoma el espíritu de Tillich y aboga por una teología correlacional, correlational theology 204, que no identifica con el modelo expresivo-experiencial criticado por Lindbeck 205. Para Tracy, la experiencia humana es también una fuente teológica, completamente independiente de las demandas de la tradición. Serían dos las fuentes imprescindibles para hacer teología: tradición y experiencia. Entre ambas hay que establecer una correlación 206. Tracy considera la relación de la teología con las demás ciencias y disciplinas humanas desde un intercambio igualitario 207 . No pueden cerrarse los cristianos en sí mismos, sino que deben entrar en conversación con el resto de lenguajes que se hablan en la actualidad. Puede haber una conversación entre todos, basada en la común experiencia humana. Hay un lenguaje común compartido.

Además Tracy tiene bien claro que el debate entre teología intratextual y correlacional es también un debate interno de los católicos 208. Según todas las voces postliberales, tanto católicas como protestantes, la aplicación de métodos correlacionales, nueva versión de lo expresivo-experiencial, habría llegado al límite de sus posibilidades. El intento de correlacionar la interpretación de la tradición con la sociedad contemporánea habría desembocado en una

bién (Guarino 1995). Un buen resumen de la oposición son (Guarino 1996, 680-685) y. (Placher 1989, cap. 10). Este último intenta una vía media, en realidad se queda en postliberal moderado.

203. El primer artículo, clásico, donde lo hace es (Tracy 1985).

204. En sentido estricto no equivale al método de correlación de Tillich aunque deriva de él. Una exposición general del método de correlación y de las dificultades que presenta puede verse en (Ormerod 1996). En el fondo las dificultades las plantea el de dónde vienen los criterios para establecer una relación entre tradición y actualidad. ¿Pura arbitrariedad del sujeto a la hora de elegir los criterios de interpretación de la tradición, o de la Escritura, con vista a su aplicación a la realidad?

205. Véase (Tracy 1990, 51), en ese artículo reivindica varias veces a Mircea Eliade. Lindbeck lo incluye en la categoría expresivo-experiencial, pero de hecho Tracy no reivindica a Schleiermacher y sí a Ricoeur y Gadamer. Reynolds reconoce que la catalogación que hace Lindbeck de Tracy no es apropiada, pero tampoco lo son las acusaciones de fideísmo, relativismo y confesionalismo que éste último hace, véase (Reynolds 1997, 45).

206. Véase (Stell 1993, 684-685). Sin olvidar tampoco que para Tracy toda afirmación teológica implica una pretensión de relevancia existencial universal. Otros autores hablan del carácter "constructivo" de la teología, así (Hodgson 1994).

207. Intercambio igualitario que no aceptan los postliberales, véase (Rigby, Hengel and O'Grady 1991, 670).

208. "Indeed, this new kind of post-Vatican II Catholic theology of Balthasar and Ratzinger is remarkably similar in method to the claim in American Protestant theology proposed by the neo-Barthian anticorrelational theologians. As Lindbeck makes clear, theology should be intratextual and not correlational" (Tracy 1989, 555). 
falta de identidad estrepitosa. Los resultados pastorales no dan para más y se impone, por lo tanto, un cambio de timón ante la pérdida de identidad y distintividad que aqueja a la Iglesia 209.

Tracy insiste en la dependencia de Lindbeck respecto a Barth 210 y en la pérdida de compromiso apologético de los postliberales 211. Estos buscan enseñar el lenguaje de la religión y no reescribir la fe en nuevos conceptos Es un nuevo tipo de confesionalismo 212, donde la Escritura es la lente por medio de la cual se ve el mundo. De ningún modo, como ya hemos dicho, admiten

209. "This methodological loss has also occasioned a substantive loss; for every tradition is in danger of losing its distinctiveness through the subtle erosions of all particularities by the illusory claims to universality of Western Enlightenment modernity. On this scenario it is time to call theology back to its own task -something like a "thick description" of the tradition for the tradition's own sake. Hence anticorrelational theologians appeal to Geertz-like understandings of theology as, in effect, a kind of descriptive religious anthropology, or they appeal to intratextual enterprises like literary criticism's ability to provide close readings of the details (...) of the Christian founding biblical narratives. Hence the anticorrelational theologians employ the later Wittgenstein and the word "foundationalism" sometimes to cover ground all the way from any Cartesian or neo-scholastic ques for certainty to any claim for the self-transcending character of reason at all. Hence the return, in Protestant theologies, to Barth's theological method and his reading of Protestant theological history. Hence the equally strong interest, in several Catholic theologies, in the theological method of Balthasar as an alternative to Rahner, Lonergan, and their successors" (Tracy 1989, 556-557). En una perspectiva opuesta (Werpehowski 1986, 285) afirma: “... the primary task of Christian theology is critically to describe and redescribe the character and relationship of Christian beliefs and practices for the purpose of sustaining and nurturing Christian identity. That identity may be conceived, in line with an intratextual norm of the biblically narrated world, as a narrative history of relationship with God, who issues to humanity a promise of redemption and fellowship in Jesus Christ. (...). Thus the Christian agent's self-expression and self-understanding is essentially involved with the meaning and implications of God's action in and with this particular promise across al dimensions of human life. These versions of Christian theology and identity are not easily reconciled with an approach to apologetics that systematically orders the comprehensibility of Christian claims and practices to representations of some general basic experience or 'faith' constitutive of Homo religiosus".

210. Este tema se ha discutido mucho como ya hemos dicho. La interpretación que hace Lindbeck de Barth, según otras voces, sería muy sesgada.

211. Frei acuñó el lema de "ad hoc apologetics", Werpehowski lo ha desarrollado. Entendiendo por apologética la presentación de la fe al mundo no creyente, se debería buscar el fundamento común compartido por cada interlocutor determinado en una conversación particular. No buscar reglas universales o aserciones generales para una conversación creyente-no creyente. La apologética tiene que ser ad hoc en cada caso. "Christian theology describes how the world looks as seen from that standpoint; it does not claim to argue from some 'neutral' or 'objective' position and indeed denies the possibility of such a position. It pursues apologetics, therefore, only on an ad hoc basis, looking for common ground with a given conversation partner but not assuming some universally aceptable standard or rationality" (Placher 1994, 117). Véase (Placher 1989, cap. 6 y 7).

212. Así se expresa (Gerrish 1988, 92). 
interpretar la Escritura desde categorías extrabíblicas 213. Otros autores insisten en el pragmatismo postliberal y en su pretensión de quedar bien tanto con la comunidad filosófica postmoderna como con la religiosa 214.

En realidad, tanto Lindbeck como Tracy se mueven dentro de la postmodernidad 215. Entendemos aquí por pensamiento moderno aquel que se ha caracterizado, en primer lugar, por la búsqueda de una fundamentación epistemológica sólida; en segundo lugar, se considera que la función primordial del lenguaje es la de representar la realidad; por último, se intenta comprender toda la realidad yendo a sus elementos últimos, a sus partes más pequeñas, a los átomos físicos o sociales -individuos-. La postmodernidad presenta justo los valores opuestos 216 .

A la teología postliberal se la ha encuadrado dentro de la corriente postmoderna, pero Tracy tampoco se encuentra alejado de ella 217. Se ha dicho que habría un creciente consenso entre los teólogos acerca de la incapacidad de contestar las cuestiones teológicas desde el pensamiento de la modernidad. La apelación al análisis neutral y objetivo de una experiencia religiosa universal, la búsqueda de una racionalidad ilustrada y pública parecen abocadas al fracaso. La modernidad implicaba racionalidad pública y objetividad. El

213. La manera de estudiar la Biblia que hace Childs encaja perfectamente con la propuesta postliberal... y con otras: "Gracias a Dios, en medio de la actual crisis de la filosofía y de la teología, se ha puesto hoy en marcha, en la misma exégesis, una nueva reflexión sobre los principios fundamentales, elaborada también gracias a los conocimientos conseguidos mediante un cuidadoso análisis histórico de los textos" y sigue en nota citando expresamente como ejemplo a Childs, así (Ratzinger 1997, 25) que previamente ha criticado, en el mismo artículo, la eficacia de los métodos histórico-críticos.

214. Ochs pone en relación a los postliberales con el pragmatismo de Peirce y con otras corrientes transmodernas de pensadores judíos, aftermodern Jewish philosophers, (Cohen, Buber, Rosenzweig, Fackenheim, Levinas, Kadushin), de quienes dice que "It is a way of analyzing religion so that the religious hermeneutic they practice may have philosophic legitimacy, and it is a way of reformulating philosophic method so that their practice of philosophy may have legitimacy in terms of their text-based religious hermeneutic. This analytic approach has performative significance, in other words, as a means of legitimating their participation in both the philosophic and religious communities. The problem is that the approach may not succeed in these terms" (Ochs 1990, 236).

215. Sobre postmodernidad y teología hay mucho escrito, véanse (Guarino 1996) y (Placher 1989).

216. Véase (Murphy and McClendon 1989, 205-207). Las caracterizaciones de la postmodernidad son muchas y muy variadas. La bibliografía es inmensa.

217. Véase (Hodgson 1994, 55). Habría dos tipos de postmodernidad: de reacción y de resistencia. La primera es la de los postliberales y neoconservadores. La segunda abarca a los que buscan una deconstrucción total de la teología para hacer algo completamente nuevo y a los revisionistas que pretender reconstruir después de deconstruir. 
tiempo de la postmodernidad es un tiempo de razón débil, de fragmentación y de elección entre alternativas metodológicas diferentes 218.

Tanto la teología postliberal como la correlacional se mueven en este ambiente. La primera sugiere que la teología debería ser postmoderna y poseer una noción postilustrada de racionalidad pública. La segunda apela a una visión postilustrada de la objetividad.

La estrategia revisionista intenta relacionar las creencias cristianas con compromisos y experiencias que toda la gente comparta. Estas convicciones creyentes sería posible defenderlas en la arena pública con criterios públicamente aceptables. No habría que abandonar la búsqueda de una racionalidad universal. Además habría que conversar con el texto y con la tradición. Aquí, en esta última conversación, cede ante la idea postmoderna. El texto no es objetivo, ni intangible al margen del lector que lo lee con criterios racionales compartidos 219 .

Para los postliberales, por el contrario, no existe correlación que valga, rechazan cualquier opción que defienda la posibilidad de que las creencias se puedan apoyar en fundamentos objetivos y universales. El texto sólo se puede leer desde dentro del mismo, no existe la posibilidad de correlación con algo que es objetivo e intangible en sí. Objetividad radical del texto.

Mientras Tracy quiere conservar alguna noción de racionalidad pública, Linbeck pretende retener la justificación de las creencias dentro de un esquema narrativo. Uno y otro son eco de la caída de la epistemología racionalista de la modernidad. Unos insisten en conversar con el texto, los otros apelan exclusivamente a leerlo. Ambos ceden a parte de la postmodernidad, cuya visión radical insiste en la imposibilidad tanto de la objetividad como de la racionalidad compartida 220 . Todo esto desemboca en posturas contrapuestas sobre el papel de la teología en la sociedad 221. De todos modos Tracy se encuentra más vinculado que Lindbeck a la modernidad.

218. Véase (Lints 1993, 657).

219. Tracy es deudor especialmente de Ricoeur.

220. Véase (Lints 1993) y (Guarino 1996). Desde otra perspectiva, la relación entre tradición y experiencia -entre correlación y absorción- (Stell 1993) ha destacado la oposición frontal entre ambos autores. La propuesta de Tracy requeriría una exposición mucho más detallada en la que no vamos a entrar y que también plantea problemas expuestos por Lints y Stell. Según éste último se trataría de buscar una "experienced tradition" o una "traditioned experience".

221. La diferente visión de revisionistas y postliberales frente a la sociedad abierta y su papel en ella puede verse en (Harvey 1994). Afirma que "the principal concern of David Tracy, who is the most prominent advocate of the publicness of theological discourse, is with 'our damaged public realm', and especially with the besieged status of reason in a postmodern 


\section{Conclusión}

En primer lugar: en la consideración postliberal de la Escritura cualquier postura al margen de la suya sería un menoscabo de la Escritura valorada en función de nuestras necesidades. Ahora bien, si partimos del sujeto perteneciente a una comunidad real de comunicación -en tensión a una comunidad ideal de comunicación- sujeto racional creado a imagen de Dios, entonces ya no se trata de dos polos enfrentados: tradición-situación del hombre actual, sino de dos polos mediados por la capacidad interpretativa del sujeto que interviene desde la racionalidad común -compartida por todos los humanosy que, en términos teológicos, es fruto de la creación. Esta racionalidad es mediada por el lenguaje y tiene pretensiones de universalidad. Los criterios interpretativos serían comunes a todo sujeto, creyente o no. En otros términos: cuando se establece una correlación -según criterios racionales, públicos, intersubjetivos- entre texto y sujeto en el mundo actual, cuando se investiga racionalmente el texto, no se actúa de modo arbitrario desde un orgullo intelectual, sino que se está cumpliendo el designio de Dios creador, en cuanto que se sacan a la luz las potencialidades del texto por medio de la razón humana creada a imagen de Dios. Esto se aplica exactamente igual a la hora de juzgar la pertenencia a cualquier institución. Quien juzga como no razonables algunos reglamentos y normas institucionales no es el altivo hombre contemporáneo secularizado, sino el creyente racional imagen de Dios. En mi opinión no es lícita la consideración postliberal de la Escritura.

world. He writes in a recent essay that the need of the public realm is twofold: 'first, to clarify the character of rationality so that the genuinely public nature of the public realm may be defended; second to clarify the sociological realities that have weakened the public realm in societies like our own, in advanced industrial and postindustrial Western democracies'. It is primarily with reference to these needs, writes Tracy, that theology has a distinctive contribution to make. Ronald Thiemann, by contrast, ties his public theology more directly to distinctively Christian beliefs and practices, while attempting to facilitate the Church's involvement in a modern, pluralistic society. More specifically, he seeks to chart a course between what he considers to be equally unacceptable alternatives: on the one hand, theologies which undermine the distinctive substance and prophetic voice of Christian convictions and practices in their eagerness to contribute to the grand experiment of liberal democracy, and on the other, theologies so intent upon preserving, the characteristic language and patterns of Christian narrative and practice that they either avoid public discourse altogether, or plunge in with a single-minded ferocity that does not take proper note of the pluralism inherent in a liberal democratic polity" (Harvey 1994, 31). Un intento distinto de analizar la relación entre teólogos postliberales y revisionistas respecto a la sociedad contemporánea es el de (Kamitsuka 1996) que aplica la noción de Rawls de reflective equilibrium, ver también (Placher 1994a, 154). 
En segundo lugar: ¿hasta qué punto añora Lindbeck un cristianismo de culto y de liturgia, de estética y presencia simbólica? Desea una Iglesia que, ante todo, produzca identidad colectiva y sentimiento de pertenencia individual. Una Iglesia que marque y distinga, que constituya una cultura propia dentro del mundo secularizado contemporáneo. Una Iglesia donde lo importante no sea la verosimilitud de sus creencias o la razonabilidad de sus propuestas morales, sino el hecho de ser precisamente eso: Iglesia, grupo, cultura, nación independiente con idioma propio. Lindbeck da la impresión de anhelar que haya cristianos como hay nuer, azande o urarinas. Añora una Iglesia cuya descripción densa hiciera feliz a cualquier etnógrafo. El problema es que difícilmente encajaría Jesucristo en la concepción de Lindbeck sobre el auténtico hombre religioso. En cuanto Jesucristo pone en cuestión, o no le interesan, los signos y conceptos que definen la identidad de su religión: la acción salvadora de Dios sobre su pueblo plasmada en el Éxodo, la noción de pueblo elegido, la observancia estricta de la ley. Tres aspectos que proporcionan identidad judía. Jesucristo no encaja en el modelo que se hace Lindbeck de pertenecer a una religión. No tiene tal identidad, sería un mal creyente. Sin embargo Jesucristo apela al Dios creador que hace llover sobre justos e injustos, al Dios del Reino universal y salvador. La Iglesia pasa del concepto de identidad judía al de identidad en Cristo. Ahora bien, los signos institucionales de identidad o de organización pueden ser vistos siempre a la luz de la primera identidad: la realidad de ser creado a imagen de Dios y por lo tanto juzgados según la racionalidad fruto de esa primera identidad. La búsqueda de identidad comunitaria a toda costa que hace Lindbeck no me parece tampoco apropiada.

En tercer lugar: el gran problema de la Iglesia actual respecto a las doctrinas estriba en la extrema debilidad de la visión proposicionalista de los contenidos doctrinales. Pero no por la visión proposicionalista en sí, sino por los contenidos doctrinales como tales. Con muchos de ellos no se puede salir a la puerta de la calle. Ahí está el fondo del asunto que no pone en cuestión Lindbeck, el qué enseñan las Iglesias. La gramática no enseña qué decir 222.

222. Una última nota. Son curiosos los análisis de las encuestas religiosas que hacen los sociólogos de la religión -de los que entre nosotros hay muchos y muy buenos-. Insisten en la religiosidad light de nuestra época y como prueba de ello tenemos los datos sobre creencias que dan una especie de fe a la carta o de supermercado religioso en los creyentes: creen en Dios el $90 \%$, en Jesucristo el $88 \%$, en el Papa el $34 \%$, en la virginidad de María el $20 \%$, en el infierno el $7 \%$, en el purgatorio el $0,6 \%$ etc. Lo mismo ocurre con las propuestas morales de las Iglesias: amor al prójimo $99 \%$, aceptan los anticonceptivos $75 \%$, etc. Qué revelan los datos, ¿la religiosidad light o las dificultades de la visión proposicional? Cabe incluso sospechar que si las encuestas se hicieran a los sociólogos, los resultados serían más escandalosos. 
En fin, es hora de acabar. La propuesta de Lindbeck y de la teología postliberal estaría muy bien si lo decisivo fuera hacer o ser Iglesia. Lástima que se equivoque de objetivo, pues la comunidad es sólo un medio. No se trata de construir una cultura propia, junto a otras muchas existentes, sueño dorado para la tesis de cualquier antropólogo que se precie. El asunto es otro. Lo decisivo es, aquí y ahora, que el antropólogo crea. Ese es el gran desafío al que Lindbeck y sus postliberales siguen sin contestar. Han errado el objetivo. ¿Hallaremos la respuesta? ¿Existe acaso?

\section{Bibliografia}

La bibliografía sobre el tema es muy amplia. La que a continuación se cita no es exhaustiva ni mucho menos. Por recomendar algo, además del libro de Lindbeck -claro está- y de las obras de los demás postliberales -la mayoría no citadas aquí-, indicaría como panorámica general de la teología anglosajona la obra de Ford (1994), original de 1989, con numerosas reimpresiones y recientemente publicada en edición ampliada en un solo volumen. Un buen resumen de Lindbeck es Michalson (1988). El artículo de Guarino (1996) es espléndido y da una panorámica general de la situación teológica actual. Comstock (1986) y Stell (1993) son también interesantes. Por último no hay que olvidar a Placher (1989).

AAVV. 1992. Hans Frei and the future of Theology. Modern Theology 8(2):101-214. Albrecht, C. 1995. Lindbeck, G. A.: Christliche Lehre als Grammatik des Glaubens. Review. Theologische Literaturzeitung 120(4):368-71.

Alston, W. P. 1995. Realism and the Christian faith. International Journal for Philosophy of Religion 38:37-60.

Auerbach, E. 1993. Mimesis. La representación de la realidad en la literatura occidental. FCE: Madrid.

Barrett, L. C. 1988. Theology as grammar: Regulative principles or paradigms and practices. Modern Theology 4(2):155-72.

Barrigar, C. J. 1995. Lindbeck's Rule Theory of Doctrine. A Philosophical and Social Theory Critique. Ph. D. Diss. Dir. M. Boutin. Montréal, McGill University.

Behrens, G. 1994. Schleiermacher contra Lindbeck on the status of doctrinal sentences. Religious Studies 30(4):399-417.

Bryant, D. 1993. Christian identity and historical change: Postliberals and historicity. Journal of Religion 73(1):31-41.

Buckley, J. J. 1985. Doctrine in the Diaspora. The Thomist 49:443-59. 
-, 1990. The hermeneutical deadlock between revelationalists, textualists, and functionalists. Modern Theology 6(4): 325-39.

-, 1992. Seeking the Humanity of God. Practices, Doctrines and Catholic Theology. The Liturgical Press: Collegeville.

Childs, B. S. 1979. Introduction to the Old Testament as Scripture. SCM Press: London.

-, 1984. The New Testament as Canon: An Introduction. SCM Press: London.

Christian, W. A. 1987. Doctrines of Religious Communities. A Philosophical Study. Yale University Press: New Haven.

Comrie, B. 1989. Universales de lenguaje y tipología lingüística. Sintaxis y Morfología. Gredos: Madrid.

Comstock, G. 1986. Truth and meaning: Ricoeur versus Frei on biblical narrative. The Journal of Religion 66(2): 117-41.

Corner, M. 1986. Review: Lindbeck, The nature of doctrine. Modern Theology 3(1): 110-13.

D'Costa, G. 1994. Theology of religions. En The Modern Theologians. An Introduction to Christian Theology in the Twentieth Century, ed. D. F. Ford, 27490. Blackwell: Oxford.

DiNoia, J. A. 1990. Varieties of religious aims: Beyond exclusivism, inclusivism, and pluralism. En Theology and Dialogue, ed. B. D. Marshall, 249-74. University of Notre Dame Press: Notre Dame.

Eckerstorfer, A. 1997. Lindbeck George A., Christliche Lehre als Grammatik des Glaubens. Review. Theologisch-Praktische Quartalschrift 145(2): 180.182.

Elkins, W. W. 1993. Learning to Say Jesus: Narrative, Identity and Community: A Study of the Hermenutics of Josiah Royce, Hans Frei, George Lindbeck, Paul Ricoeur and the Gospel of Mark. Ph. D. Diss. Dir. P. Ochs. Drew University.

Emmanuel, S. M. 1989. Kierkegaard on doctrine: A post-modern interpretation. Religious Studies 25(3): 363-78.

Ford, D. F. 1986. The Nature of Doctrine. Review. Journal of Theological Studies 37: 277-82.

—, 1996. On being theologically hospitable to Jesus Christ: Hans Frei achievement. Journal of Theological Studies 46(2): 532-46.

-, ed. 1994. The Modern Theologians. An Introduction to Christian Theology in the Twentieth Century. Blackwell: Oxford.

Frei, H. W. 1974. The Eclipse of Biblical Narrative. A Study in Eighteenth and Nineteenth Century Hermeneutics. Yale University Press: New Haven.

-, 1975. The Identity of Jesus Christ: The Hermeneutical Bases of Dogmatic Theology. Fortress Press: Philadelphia.

-, 1990a. Epilogue: George Lindbeck and the nature of doctrine. En Theology and Dialogue, ed. B. D. Marshall, 275-82. University of Notre Dame Press: Notre Dame.

—, 1990b. "Narrative" in christian and modern reading. En Theology and Dialogue, ed. B. D. Marshall, 149-63. University of Notre Dame Press: Notre Dame.

-, 1992. Types of Christian Theology. Yale University Press: New Haven.

-, 1993. Theology and Narrative. Selected Essays. Eds G. Hunsinger and W. C. Placher. Oxford University Press: Oxford. 
Gauchet, M. 1985. Le désenchantement du monde. Une histoire politique de la religion. Gallimard: Paris.

Geertz, C. 1987. La interpretación de las culturas. Gedisa: México.

Gerrish, B. A. 1988. The nature of doctrine. Journal of Religion: 87-92.

Giordano, O. 1995. Religiosidad popular en la Alta Edad Media. Gredos: Madrid.

Godlove, T. F. 1987. Two kinds of narrative coherence: Transcendental and religious. The Journal of Religion 67(4): 456-73.

Goldberg, M. 1988. God, action and narrative: Which narrative? which action?; which God? Journal of Religion 68(1): 39-56.

Grimes, R. 1986. Of words the speaker, of deeds the doer. The Journal of Religion 66(1): $1-17$.

Guarino, T. 1995. "Spoils from Egypt": Contemporary Theology and Non-foundationalist Thought. Laval Théologique et Philosophique 51(3): 573-87.

-, 1996. Postmodernity and five fundamental theological issues. Theological Studies 57(4): 654-89.

Harvey, B. A. 1994. Insanity, theocracy, and the public realm: Public theology, the church, and the politics of liberal democracy. Modern Theology 10(1): 27-57.

Hauerwas, S. 1981. A Community of Character: Toward a Constructive Christian Social Ethic. University of Notre Dame Press: Notre Dame.

-, 1983. The Peaceable Kingdom. University of Notre Dame Press: Notre Dame.

-, 1985. Character and the Christian Life. University of Notre Dame Press: Notre Dame.

-, 1986. Some theological reflections on Gutierrez's use of 'liberation' as a theological concept. Modern Theology 3(1): 67-76.

Herholdt, S. J. 1992. Grammatikale Theologie? 'n kritiese Beskrywing van George A. Lindbeck se kultuur-linguistiese Model vir Teologie. Ph. D. Diss. Dir. D. J. Smith. Western Cape.

Hierro S. Pescador, J. 1980. Principios de Filosofía del Lenguaje. Alianza: Madrid.

Hodgson, P. C. 1994. Winds of the Spirit. A Constructive Christian Theology. SCM Press: London.

Hunsinger, G. 1987. Beyond literalism and expressivism: Karl Barth's hermeneutical realism. Modern Theology 3: 209-23.

-, 1992. Hans Frei as Theologian: The Quest for Generous Orthodoxy. Modern Theology 8(2): 103-28.

-, 1993. Truth as self-involving: Barth and Lindbeck on the cognitive and performative aspects of truth in theological discourse. Journal of the American Academy of Religion 61(1): 41-56.

Jenson, R. W. 1992. The Hauerwas project. Modern Theology 8(3): 285-95.

Kamitsuka, D. G. 1996. The Justification of Religious Belief in the Pluralistic Public Realm: Another Look at Postliberal Apologetics. The Journal of Religion 76 (4): 588-606.

-, 1997. Salvation, liberation and christian character formation: Postliberal and liberation theologians in dialogue. Modern Theology 13(2): 171-89.

Kasper, W. 1989. Postmoderne Dogmatik? Zu einer nordamerikanischen Grundlagendiskussion. En Der Weg Zum Menschen. Zur Philosophischen und Theo- 
logischen Anthropologie (Festschrift Alfons Deissler), Hrsg R. Mosis and L. Ruppert, 265-74. Freiburg i. Br.

Kelsey, D. H. 1975. The Uses of Scripture in Recent Theology. Fortress: Philadelphia.

-, 1990. Church discourse and public realm. En Theology and Dialogue, ed. B. D. Marshall, 7-33. University of Notre Dame Press: Notre Dame.

Lash, N. 1990. When did the theologians lose interest in theology? En Theology and Dialogue, ed. B. D. Marshall, 131-47. University of Notre Dame Press: Notre Dame.

Lauritzen, P. 1987. Is "narrative" really a panacea? The use of "narrative" in the work of Metz and Hauerwas. The Journal of Religion 67(3): 322-39.

Lawson, E. T., and R. N. McCauley. 1993. Crisis of conscience, riddle of identity. Making space for a cognitive approach to religious phenomena. Journal of the American Academy of Religion 61(2): 201-23.

Leech, G. 1974. Semántica. Alianza: Madrid.

Lindbeck, G. A. 1984. The Nature of Doctrine. Religion and Theology in a Postliberal Age. Westminster Press/SPCK: Philadelphia/London.

-, 1994a. Christliche Lehre als Grammatik des Glaubens. Religion und Theologie im Postliberalen Zeitalter. Introd. de H. G. Ulrich y R. Hütter. Kaiser: Gütersloh.

-, 1994. Ecumenical Theology. En The Modern Theologians, ed. D. F. Ford, vol II, pp. 255-73. Blackwell: Oxford.

Lints, R. 1993. The Postpositivist Choice. Tracy or Lindbeck? Journal of the American Academy of Religion 61(4): 655-77.

López Sáenz, M. C. 1997. El paradigma del texto en la filosofía hermenéutica. Pensamiento 53(206): 215-42.

Macquarrie, J. 1984-85. Usefulness of doctrines. Expository Times 96(10): 315-16.

Marshall, B. D. 1990. Absorbing the world: Christianity and the universe of truths. En Theology and Dialogue, ed. B. D. Marshall, 69-102. University of Notre Dame Press: Notre Dame.

-, ed. 1990. Theology and Dialogue: Essays in Conversation with George Lindbeck. Notre Dame University Press: Notre Dame.

Meeks, W. A. 1988. Los primeros cristianos urbanos. Sígueme: Salamanca.

-, 1992. El mundo moral de los primeros cristianos. Desclée: Bilbao.

Michalson, G. E. 1988. The response to Lindbeck. Modern Theology 4(2):107-20.

Milbank, J. 1988. Stanley Hauerwas: Character and the Christian Life and Stanley Hauerwas: Against the nations. Review. Modern Theology 4(2): 211-16.

Murphy, N., and J. W. McClendon. 1989. Distinguishing modern and postmodern theologies. Modern Theology 5(3): 191-214.

Neville, R. C. 1993. Religious Studies and Theological Studies. Journal of the American Academy of Religion 61(2): 185-200.

Oakes, E. T. 1992. Apologetics and the Pathos of Narrative Theology. The Journal of Religion 72(1): 37-58.

Ochs, P. 1990. A rabbinic pragmatism. En Theology and Dialogue, ed. B. D. Marshall, 213-48. University of Notre Dame Press: Notre Dame.

Ormerod, N. 1996. Quarrels with the method of correlation. Theological Studies 57(4): 707-19.

Ott, H. 1994. Apologetik des Glaubens. Grundprobleme einer dialogischen Fundamentaltheologie. Wissenschaftliche Buchgesellschaft: Darmstadt. 
Pals, D. L. 1996. Seven Theories of Religion. Oxford University Press: Oxford.

Pastor, F. A. 1997. La cuestión de lo Incondicionado. Dialéctica y revelación de lo sagrado en Paul Tillich. Gregorianum 78(2):267-308.

Phillips, D. Z. 1988. Lindbeck's Audience. Modern Theology 4(2): 133-54.

Placher, W. C. 1985. Revisionist and postliberal theologies and the public character of theology. The Thomist 49:392-416.

-, 1989. Unapologetic Theology. A Christian Voice in a Pluralistic Conversation. Westminster / Knox: Louisville.

-, 1994a. Gospels'ends: Plurality and ambiguity in biblical narratives. Modern Theology 10(2): 143-63.

-, 1994. Postliberal Theology. En The Modern Theologians. An Introduction to Christian Theology in the Twentieth Century, ed. D. F. Ford, 115-28. Blackwell: Oxford.

Power, W. L. 1987. Homo religiosus: From a semiotic point of view. International Journal for Philosophy of Religion 21(2): 65-81.

Ratzinger, J. 1997. Situación actual de la fe y la teología. Communio 19(1): 13-27.

Reynolds, T. 1997. Walking apart, together: Lindbeck and McFague on Theological Method. The Journal of Religion 77(1): 44-67.

Richards, J. W. 1997. Truth and Meaning in George Lindbeck's The Nature of Doctrine. Religious Studies 33(1): 33-53.

Rigby, P., J. v. d. Hengel y P. O'Grady. 1991. The nature of doctrine and scientific progress. Theological Studies 52(4): 669-88.

Root, M. 1990. Identity and difference: The ecumenical problem. En Theology and Dialogue, ed. B. D. Marshall, 165-90. University of Notre Dame Press: Notre Dame.

Sanks, T. H. 1993. David Tracy's theological project: An overview and some implications. Theological Studies 54(4): 698-727.

Stell, S. L. 1993. Hermeneutics in Theology and the Theology of Hermeneutics. Beyond Lindbeck and Tracy. Journal of the American Academy of Religion 61(4):679-703.

Surin, K. 1988. Many religions and the one true faith: an examination of Lindbeck's chapter three. Modern Theology 4(2): 187-209.

Sykes, J. 1989. Narrative accounts of biblical authority: The need for a doctrine of revelation. Modern Theology 5(4): 327-42.

Thiemann, R. F. 1985. Revelation and Theology: The Gospel as Narrated Promise. University of Notre Dame Press: Notre Dame.

Tilley, T. W. 1989. Incommensurability, intratextuality, and fideism. Modern Theology 5(2): 87-111.

Tracy, D. 1985. Lindbeck's new program for Theology: A reflection. The Thomist 49: 460-472.

,- 1989 . The uneasy alliance reconceived: Catholic theological method, modernity, and postmodernity. Theological Studies 50(3): 548-70.

-, 1990. On reading the scriptures theologically. En Theology and Dialogue, ed. B. D. Marshall, 35-68. University of Notre Dame Press: Notre Dame.

Wainwright, G. 1986. Bemerkungen aus Amerika zu Dietrich Ritschls "Logik der Theologie." Evangelische Theologie 46(6): 555-61. 
—, 1988. Ecumenical dimensions of Lindbeck's "Nature of Doctrine." Modern Theology 4(2):121-32.

Welch, S. 1997. Communitarian ethics after Hauerwas. Studies in Christian Ethics 10(1): 82-95.

Werpehowski, W. 1986. Ad Hoc Apologetics. The Journal of Religion 66(3):282-301. Wiedenhofer, S. 1988. Lindbeck, G. A.: The Nature of Doctrine. Review. Theologische Revue 84(1): 47-49.

Williams, S. 1988. Lindbeck's regulative Christology. Modern Theology 4(2):173-86.

Wilson, J. R. 1994. By the logic of the gospel: Proposal for a theology of culture. Modern Theology 10(4): 401-14.

Zorn, H. 1995. Grammar, Doctrines, and Practice. The Journal of Religion 75(4): 509-20.

Fernando Joven

Estudio Teológico Agustiniano

Valladolid 